\title{
TITLE:
}

\section{Controlled Polymerization in Flow Microreactor Systems}

$\operatorname{AUTHOR}(\mathrm{S})$ :

Nagaki, Aiichiro; Yoshida, Jun-ichi

\section{CITATION:}

Nagaki, Aiichiro ... [et al]. Controlled Polymerization in Flow Microreactor Systems. Advances in Polymer Science 2012, 259: 1-50

ISSUE DATE:

2012-08-22

URL:

http://hdl.handle.net/2433/196844

\section{RIGHT:}

The final publication is available at Springer via http://dx.doi.org/10.1007/12_2012_179; This is not the published version. Please cite only the published version.; この論文は出版 社版でありません。引用の際には出版社版をご確認ご利用ください。 
Flow-Microreactor-System Controlled Polymerization

Aiichiro Nagaki, Jun-ichi Yoshida

1 Introduction

1.1 Characteristic Features of Flow Microreactors

1.2 Cationic Polymerization

1.2.1 Basic Principles of Cationic Polymerization of Vinyl Monomers

1.2.2 Controlled/living Cationic Polymerization of Vinyl Monomers Based on Cation Stabilization

1.2.3 Controlled/living Cationic Polymerization of Vinyl Monomers Based on Cation Stabilization Using Flow Microreactor Systems

1.2.4 Controlled/living Cationic Polymerization of Vinyl Ethers Without Stabilizing Carbocationic Intermediates Using Flow Microreactor Systems

1.2.4.1 Concept of Flow-microreactor-system-controlled Polymerization Technology

1.2.4.2 “Cation Pool” Initiated Polymerization of Vinyl Ethers Using Flow Microreactor Systems

1.2.4.3 Brønsted Acid Initiated Polymerization of Vinyl Ethers Using Flow Microreactor Systems

1.2.5 Cationic Polymerization of Diisopropenylbenzenes Using Flow Microreactor Systems

1.3 Anionic Polymerization

1.3.1 Controlled/living Anionic Polymerization of Vinyl Monomers

1.3.2 Controlled/living Anionic Polymerization of Styrenes

1.3.2.1 Controlled/living Anionic Polymerization of Styrenes in Polar Solvent Using Flow Microreactor Systems

1.3.2.2 Controlled/living Anionic Polymerization of Styrenes in Nonpolar Solvent Using Flow Microreactor Systems

1.3.3 Controlled/living Anionic Polymerization of Alkyl Methacrylates Using Flow Microreactor Systems

1.3.4 Controlled/living Anionic Block Copolymerization of Styrenes and Alkyl Methacrylates Using Integrated Flow Microreactor Systems

1.4 Radical Polymerization

1.4.1 Free Radical Polymerization Using Flow Microreactor Systems

1.4.2 Living Radical Polymerization Using Flow Microreactor Systems

1.4.2.1 Atom Transfer Radical Polymerization (ATRP) Using Flow Microreactor Systems

1.4.2.2 Reversible Addition-fragmentation Chain Transfer Radical Polymerization (RAFT) Using Flow Microreactor Systems

1.4.2.3 Nitroxide-mediated Radical Polymerization Using Flow Microreactor Systems

1.5 Ring Opening Polymerization Using Flow Microreactor Systems

1.6 Polycondensation Using Flow Microreactor Systems

1.7 Ziegler-Natta polymerization Using Flow Microreactor Systems 
1.8 Fabrication of Polymeric Structures inside Microchannels Using Fluid Flow

1.8.1 Polymerization on the Surface of Microchannels

1.8.2 Fabrication of Polymer Membranes inside Microchannels

1.9 Industrial Applications

\title{
1.10 Conclusion
}

\begin{abstract}
Flow microreactors are expected to make a revolutionary change in chemical synthesis involving various fields of polymer synthesis. In fact, extensive studies on cationic polymerization, anionic polymerization, radical polymerization, coordination polymerization, polycondensation, and ring-opening polymerization using flow microreactor systems have opened new possibilities in polymer chemistry and polymer industry. This article provides, in a concise form, a current overall picture of polymerization using flow microreactors.
\end{abstract}

\section{Introduction}

Microtechnology is no longer the field of electronics, but is now moving into many different areas of science and engineering, including mechanics, optics, and fluids, because it provides better efficiencies while also answering the demands of society for conserving resources and energy. Following remarkable advances in microfabrication technology, microtechnology has been used in the field of chemistry since the 1990s. Micro devices that are used for chemical reactions are called microreactors; reactors with micrometer-size channels for conducting chemical reactions.

Microreactors are normally set up as flow-type reactors (flow microreactors) with a continuous flow of a solution through the reaction chamber. Nowadays, chemical synthesis in flow microreactors has received significant research interests from both academia and industry [1-24]. Recent investigations revealed significant features of flow microreactor systems involving fast mixing stemming from short diffusion paths and fast heat transfer by virtue of high surface-to-volume ratios, which are advantageous to increase the selectivity of chemical reactions [25-28]. Short residence time in a microchannel is beneficial for controlling highly reactive intermediates [29-45]. By taking advantages of such features of flow microreactor systems, various chemical reactions for organic synthesis have been developed so far [46-56].

Polymerization reactions that convert small molecules into macro molecules by repeating chemical reactions are a fascinating field in the applications of flow microreactors. Extensive studies on cationic polymerization, anionic polymerization, radical polymerization, coordination polymerization, polycondensation, and ring-opening polymerization using flow microreactor systems have been carried out so far. Reviews on various polymerization methods in microreactors have been reported by Hessel et al., Wilms et al., Mcquade et al. and Serra et al [57-61]. The main objective of this article is to provide, in a 
concise form, a current overall picture of polymerization using flow microreactors, especially from a view point of industrial applications. Because of space limitations, polymer particle synthesis will not be discussed here. Serra and Chang has reported an excellent review on synthesis of polymer particles with an improved control of their sizes, size distributions, morphologies and compositions using microreactors [62].

\subsection{Characteristic Features of Flow Microreactors}

Flow microreactors can influence the very essence of chemical reactions, because of the following characteristic features derived from their small size and flow nature.

(1) Fast mixing [63, 64]: Many chemical reactions involve combining two substances, and for this reason mixing to achieve homogeneity in solution is very important, especially for fast reactions. Mixing occurs due to molecular diffusion. According to the theory of molecular diffusion, the time needed for molecular diffusion is proportional to the square of the length of the diffusion path. Therefore, the marked shortening of the diffusion path in a microreactor results in a mixing speed that is unobtainable in a macroreactor. The working principle of a typical micromixer (i.e., a multilamination-type micromixer [65]) is shown in Figure 1. The solutions to be mixed are distributed into several segments of flows of small width by using the microstructure. The mixing takes place through the interfaces of the segments of flows by virtue of the short diffusion path.

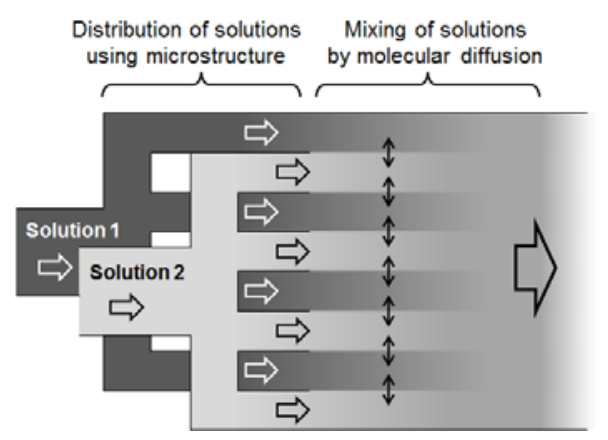

Figure 1 Working principles of a multilamination-type micromixer.

(2) Temperature control: Heat is transferred between the interior and exterior of a reactor via the reactor surface according to the theory of heat transfer. Therefore, area per unit volume of the reactor is a crucial factor for heat transfer. Generally, volume is equal to the length cubed, while surface area is equal to length squared. When the length is shortened, surface-to-volume ratio increases. Thus, a feature of microspaces compared to macrospaces is that they have larger surface-to-volume ratios (Figure 2). Because microreactors have a greater surface area per unit volume than macroreactors, heat transfer occurs rapidly in a flow microreactor, enabling fast cooling/heating and, hence, precise temperature control. 


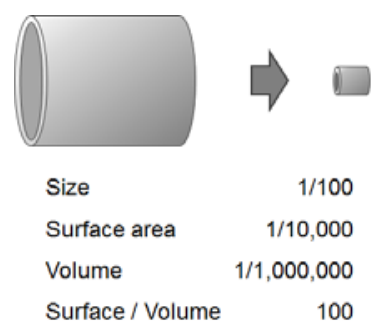

Figure 2 Numerical aspects of decreasing size.

Another characteristic feature of microreactors derived from their much greater surface-to-volume ratios is that they make phase-boundary reactions such as gas/liquid, liquid/liquid, or solid/liquid reactions more efficient. This feature of flow microreactors is also advantageous for photochemical [66-75] and electrochemical [76-86] reactions, which have received significant attention from a viewpoint of environmentally benign synthesis.

(3) Residence time control: The length of time that the solution remains inside the reactor is called the residence time. In flow reactors, the residence time increases with the length of the channel and decreases with the flow speed. In flow microreactors the residence time can be greatly reduced by shortening the length of the microchannels. This feature of flow microreactors is extremely useful in controlling reactions involving unstable short-lived reactive intermediates. Unstable reactive species can be transferred to another location to be used in the next reaction before they decompose (Figure 3). By taking advantage of this feature, chemical transformations that are very difficult or impossible in macroreactors can be achieved in microreactors [87-90].

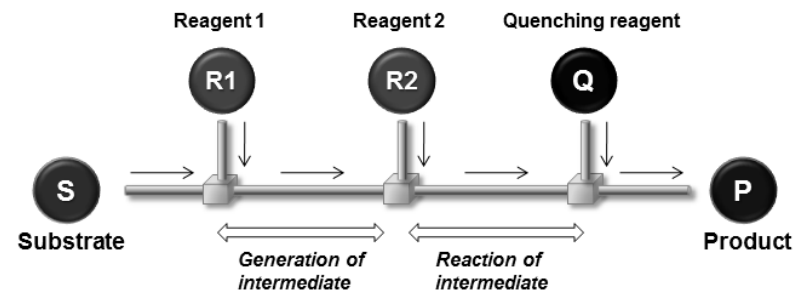

Figure 3 Principle of generation and reaction of unstable short-lived reactive intermediates based on residence time control in a flow microreactor.

\subsection{Cationic Polymerization}

\subsubsection{Basic Principles of Cationic Polymerization of Vinyl Monomers}

Cationic polymerization [91, 92] is one of the most fundamental methods for synthesizing polymers. Although there are several types of cationic 
polymerization, the most important one is cationic polymerization of vinyl monomers having a cation stabilizing group (Y) (Scheme 1).

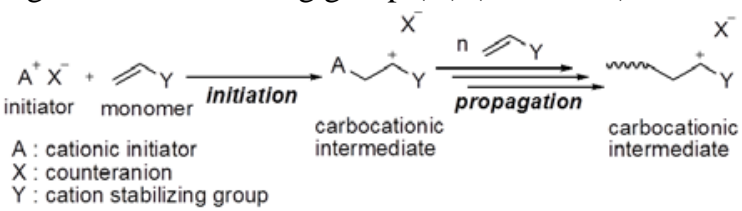

Scheme 1 Cationic polymerization of vinyl monomers.

The initiation usually involves the addition of a cationic species $\left(\mathrm{A}^{+}\right)$to a vinyl monomer to produce a carbocationic intermediate associated with a counter anion $\left(\mathrm{X}^{-}\right)$, which is derived from the initiator. In general, proton acids or carbocations generated from their precursors by acid promoted ionization reactions [93-95], are used as initiators. The carbocationic intermediate thus obtained adds to another molecule of the monomer to give the next carbocationic intermediate, which adds to another monomer (propagation step). The carbocationic intermediates are usually highly reactive and unstable. They undergo a number of side reactions such as chain transfer and termination. Chain transfer to monomer is the most problematic from a view point of molecular weight control and molecular weight distribution control. Namely, the $\beta$-proton of the carbocationic intermediate is inherently acidic because of the positive charge on the carbon. On the other hand, monomers used in cationic polymerization are inherently nucleophilic or basic. Therefore, the proton abstraction from the carbocationic intermediate by the monomer is inevitable and is very difficult to suppress (Scheme 2).

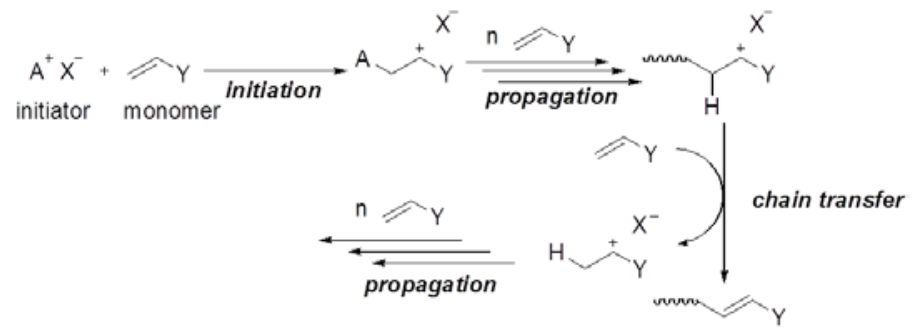

Scheme 2 Chain transfer as a side reaction in cationic polymerization of vinyl monomers.

\subsubsection{Controlled/living Cationic Polymerization of Vinyl Monomers Based on Cation Stabilization}

One of the most important breakthroughs in cationic polymerization is the discovery of living cationic polymerization. The inherent and serious drawback of cationic vinyl polymerization is instability of the carbocationic intermediates, which causes the chain transfer leading to the formation of 
polymers of broad molecular weight distribution. Higashimura and Sawamoto et al. proposed and verified experimentally that living cationic polymerization can be attained by stabilizing the carbocationic intermediate by nucleophilic interaction with a suitably nucleophilic counter anion or an externally added Lewis base (B) (Scheme 3) [96-98].

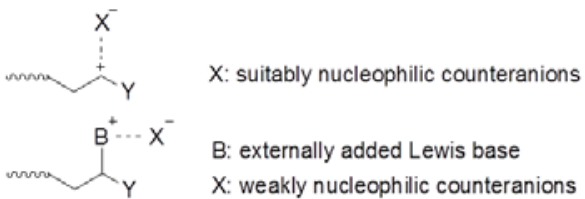

Scheme 3 Stabilization of the carbocationic intermediate by nucleophilic interaction with a suitably nucleophilic counteranion or an externally added Lewis base.

In both methods the positive charge of the carbocationic center is reduced and thereby the acidity of the $\beta$-proton is reduced to suppress the chain transfer. As a result, good molecular weight control and molecular weight distribution control are attained. On the basis of the principles, a number of initiating systems have been developed for living cationic polymerization [99].

\subsubsection{Controlled/living Cationic Polymerization of Vinyl Ethers Based on Cation Stabilization Using Flow Microreactor Systems [100]}

Living cationic polymerization of vinyl ethers initiated by $\mathrm{SnCl}_{4} / \mathrm{RCl}$ catalytic system can be carried out in a continuous microreactor system, which consists of a mutilamination micromixer $\mathbf{M}$ (channel width $=40 \mu \mathrm{m}, \mathrm{IMM}$ ) and a micro tube reactor $\mathbf{R}$ (Figure 4). A solution of a monomer and an initiator's precursor is mixed with a solution of $\mathrm{SnCl}_{4}$ using the micromixer at $-78{ }^{\circ} \mathrm{C}$ and the resulting mixture was allowed to react in the microtube reactor at the same temperature. For example, isobutyl vinyl ether (IBVE) can be polymerized using functionalized initiators to obtain the end-functionalized polymers of narrow molecular weight distribution $(\mathrm{Mw} / \mathrm{Mn}<1.2)$. Block copolymerization of IBVE and $n$-butyl vinyl ether (NBVE) can also be successfully achieved using a microreactor system consisting of two micromixers and two microtube reactors to obtain the corresponding copolymer of narrow molecular weight distribution $(\mathrm{Mw} / \mathrm{Mn}<1.3)$

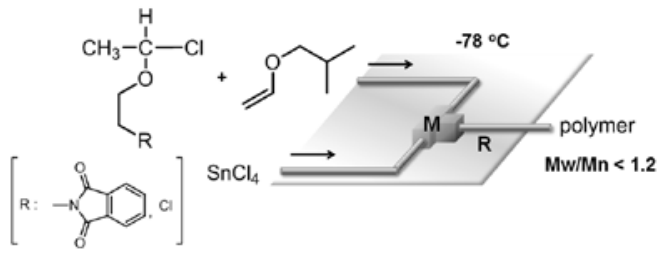


Figure 4 A flow microreactor system for controlled/living cationic polymerization of vinyl ether initiated by $\mathrm{SnCl}_{4}$. $\mathbf{M}$ : IMM micromixer, $\mathbf{R}$ : microtube reactor.

\subsubsection{Controlled/living Cationic Polymerization of Vinyl Ethers Without} Stabilizing Carbocationic Intermediates Using Flow Microreactor Systems

One of the major drawbacks of the controlled/living cationic polymerization based on stabilization of the carbocationic intermediates is slow propagation. Because the concentration of the active propagating species is very low because of the equilibrium between active species and dormant species, overall polymerization reactions are much slower than those without the equilibrium. Another important drawback of the controlled/living polymerization is the use of additives such as Lewis bases. Such additives should remain in polymer products and are generally rather difficult to be removed from the polymer products.

Recently, it has been demonstrated that good molecular weight control and molecular weight distribution control can be attained by using microreactor systems without stabilizing the carbocationic intermediates. The concept of this new technology (flow-microreactor-system-controlled polymerization) is described in the following section.

\subsubsection{Concept of Flow-microreactor-system-controlled Polymerization Technology}

Molecular weight and molecular weight distribution control in polymerization can be seen as control of competitive consecutive reactions as shown in Scheme 4, where $\mathbf{A}$ is an initiator and $\mathbf{B}$ is a monomer.

$$
\text { A } \underset{k_{1}}{\stackrel{B}{\longrightarrow}} \mathbf{P}_{1} \frac{\mathbf{B}}{k_{2}} \mathbf{P}_{2} \frac{\mathbf{B}}{k_{3}} \mathbf{P}_{3} \longrightarrow \text { polymer }
$$

Scheme 4 Polymerization as a competitive consecutive reaction.

In the first step, A (initiator) reacts with $\mathbf{B}$ (monomer) to produce the first carbocationic intermediate $\mathbf{P}_{\mathbf{1}}$. In the second step, $\mathbf{P}_{\mathbf{1}}$ reacts with another monomer to produce the second carbocationic intermediate $\mathbf{P}_{2}$. Further reactions lead to polymer formation. If the initiation step to give $\mathbf{P}_{\mathbf{1}}$ is faster than propagation steps, there is a chance to get good molecular weight control and molecular weight distribution control based on monomer/initiator ratios. However, this is the case only when the reactions are slower than the mixing and the reactions proceed in a homogeneous solution. If reactions are faster than mixing a significant amount of $\mathbf{P}_{2}$ (and $\mathbf{P}_{\mathbf{n}}(\mathrm{n}>2)$ ) is formed before $\mathbf{A}$ is consumed even if $k_{1}>>k_{2}$. In this case, it is meaningless to define concentration of $\mathbf{A}$ and $\mathbf{B}$ based on the total volume of the solution, because the solution is not homogeneous, and the product selectivity is not determined by kinetics. This problem is similar to the problem of disguised chemical selectivity for competitive consecutive reactions [101], this problem can be solved by extremely fast micromixing. In fact, the enhancement of product selectivity of competitive consecutive reactions [102] such as Friedel-Crafts 
reactions [103, 104], [4+2] cycloaddition reactions [105, 106], lithiation of dibromobiaryls [107-110], iodination of aromatic compounds [111, 112], and the reaction of a Grignard reagent with $\mathrm{B}(\mathrm{OMe})_{3}$ [113] by virtue of extremely fast micromixing using flow microreactor systems has been reported. These successful results suggest the possibility of molecular weight and molecular weight distribution control by using flow microreactor systems.

In flow-microreactor-system-controlled polymerization extremely fast mixing of an initiator solution and a monomer solution is achieved by extremely fast mixing leading to selective initiation. Propagation proceeds based on the monomer/initiator ratio under homogeneous conditions, and therefore polymers are obtained with good molecular weight and molecular weight distribution control. Minimizing local deviation of temperature by fast heat transfer through the wall of a microreactor by virtue of high surface-to-volume ratios is also important because polymerization processes are usually highly exothermic.

\subsubsection{2 "Cation Pool" Initiated Polymerization of Vinyl Ethers Using Flow Microreactor Systems}

Flow-microreactor-system-controlled cationic polymerization requires extremely reactive initiators, and highly reactive organic cations serve as effective initiators for this method. Usually organic cations such as carbenium ions and onium ions are generated by an acid-promoted reversible process from their precursors. Yoshida et al. have developed the "cation pool" method [114, 115] in which organic cations are generated irreversibly by low temperature electrolysis and are accumulated in relatively high concentration in the absence of nucleophiles. $N$-Acyliminium ions [116], alkoxycarbenium ions [117-122], diarylcarbenium ions [123, 124], and glycosyl triflate [125] have been generated and accumulated by this method. Yoshida et al. reported that $N$-acyliminium ion pools serve as extremely reactive initiators for cationic polymerization in flow microreactors.

A pool of an $N$-acyliminium ion is generated by low temperature electrochemical oxidation of its precursor, a $\alpha$-silyl-substituted $N$-acylamine. Cationic polymerization of butyl vinyl ether (NBVE) using the $N$-acyliminium ion as an initiator in a conventional batch reactor gives the polymer in a quantitative yield after quenching with $i-\mathrm{Pr}_{2} \mathrm{NH} / \mathrm{CH}_{2} \mathrm{Cl}_{2}$, but the molecular weight distribution is broad $(\mathrm{Mn}=5700, \mathrm{Mw} / \mathrm{Mn}=2.56)$. The reverse addition sequence (the $\mathrm{N}$ acyliminium ion to the monomer) gives rise to a similar molecular weight distribution (quantitative yield, $\mathrm{Mn}=13100, \mathrm{Mw} / \mathrm{Mn}=2.25$ ). The simultaneous addition of a monomer solution and a solution of the $N$-acyliminium ion does not improve the molecular weight distribution control (quantitative yield, $\mathrm{Mn}=$ $24500, \mathrm{Mw} / \mathrm{Mn}=2.43$ ). The molecular weight, however, strongly depends upon the method of mixing because the rate of the polymerization is so fast. In contrast, the use of a flow microreactor system consisting of two micromixers (M1 and M2) and two microtube reactors (R1 and R2) shown in Figure 5 leads to excellent control of molecular weight and its distribution $(\mathrm{Mn}=6700, \mathrm{Mw} / \mathrm{Mn}=1.14)$ 
[126]. Solutions of $N$-acyliminium ion [127] and NBVE are introduced to M1 by the syringe pump technique at $-78^{\circ} \mathrm{C}$. Then, the reaction mixture is introduced to a microtube reactor $(\mathbf{R 1})(\phi=1.0 \mathrm{~mm}, 10 \mathrm{~cm})$, in which the polymerization takes place. In the final stage, $i-\mathrm{Pr}_{2} \mathrm{NH} / \mathrm{CH}_{2} \mathrm{Cl}_{2}$ is introduced at $\mathbf{M} 2$ to quench the polymerization. The polymerization takes place quite effectively and is complete within the residence time of $0.05 \mathrm{~s}$ to give the polymer with narrow molecular weight distribution $(\mathrm{Mn}=6700, \mathrm{Mw} / \mathrm{Mn}=1.14)$. The molecular weight can be controlled by changing the monomer/initiator ratio. The molecular weight (Mn) increases linearly with the amount of NBVE, indicating that chain transfer reaction does not play significant roles in this system.

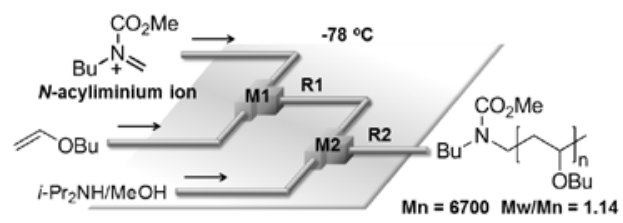

Figure 5 Flow microreactor system for polymerization of vinyl ether initiated by $\mathrm{N}$-acyliminium ion (cation pool). M1, M2: micromixer; R1, R2: microtube reactor.

The effect of the flow rate on molecular weight distribution (Table 1, runs 4-6) indicates the importance of mixing, because it is known that mixing efficiency decreases with a decrease in the flow rate in the micromixer [128]. Reaction temperature is also important for controlling molecular weight distribution. Mw/Mn increases with an increase in the temperature (runs 4, 7, 8, and 9). Anyway, a high level of molecular weight control can be achieved by control of the initiation process by fast micromixing. Precise control of polymerization temperature also seems to be responsible for the remarkable control.

Table 1 Cationic polymerization of NBVE initiated by $N$-acyliminium ion using a flow microreactor system

\begin{tabular}{cccccc}
\hline run & $\begin{array}{c}\text { monomer } \\
\text { (equiv) }\end{array}$ & $\begin{array}{c}\text { flow rate } \\
(\mathrm{mL} / \mathrm{min})\end{array}$ & $\begin{array}{c}\text { Temperature } \\
\left({ }^{\circ} \mathrm{C}\right)\end{array}$ & $\mathrm{Mn}$ & $\mathrm{Mw} / \mathrm{Mn}$ \\
\hline 1 & 10 & 5.0 & -78 & 1500 & 1.40 \\
2 & 25 & 5.0 & -78 & 2900 & 1.26 \\
3 & 35 & 5.0 & -78 & 4400 & 1.17 \\
4 & 50 & 5.0 & -78 & 6700 & 1.14 \\
5 & 50 & 3.0 & -78 & 5600 & 1.35 \\
6 & 50 & 1.0 & -78 & 6200 & 2.84 \\
7 & 50 & 5.0 & -48 & 8200 & 1.30 \\
8 & 50 & 5.0 & -27 & 5500 & 1.34 \\
9 & 50 & 5.0 & 0 & 6500 & 1.61 \\
\hline
\end{tabular}


The polymer end is living within the residence time of $0.5 \mathrm{~s}$ at $-78{ }^{\circ} \mathrm{C}$, and can be effectively trapped by allyltrimethylsilane. Moreover, the present "cation pool” initiated polymerization using a microreactor system can be applied to other vinyl ethers such as isobutyl vinyl ether (IBVE) and tert-butyl vinyl ether (TBVE) to obtain the corresponding polymers $(\mathrm{Mw} / \mathrm{Mn}=1.12$ (IBVE), $\mathrm{Mw} / \mathrm{Mn}=1.50$ (TBVE)), though the corresponding polymerization using batch macro reactors results in much poorer molecular weight distribution control $(\mathrm{Mw} / \mathrm{Mn}=4.31$ (IBVE), $\mathrm{Mw} / \mathrm{Mn}=2.29(\mathrm{TBVE})$ ).

\subsubsection{Brønsted Acid Initiated Polymerization of Vinyl Ethers Using Flow Microreactor Systems}

Proton addition is one of the most simple and straightforward methods for the initiation of cationic polymerization. Brønsted acids are effective for this purpose. However, if we use a weak Brønsted acid, i.e. a conjugate acid of a strong nucleophilic anion, the addition of a Lewis acid is necessary to establish a reversible activation of a covalent end group for effective propagation. On the other hand, if we use a strong Brønsted acid, i.e. a conjugate acid of an extremely weak nucleophilic anion, the addition of a Lewis base is required to stabilize the carbocationic propagating polymer ends [129]. In the absence of a Lewis base, highly ionic polymer ends are too reactive, and participate in transfer reactions by loss of $\beta$-protons leading to a very broad molecular weight distribution.

Trifluoromethanesulfonic acid (TfOH) is an effective initiator for cationic polymerization. For example, TfOH-initiated polymerization of isobutyl vinyl ether (IBVE) in 1,2-dichloroethane using a macro batch reactor [130] is complete within $10 \mathrm{~s}$ at $-25^{\circ} \mathrm{C}$. The molecular weight distribution is, however, rather broad and $\mathrm{Mw} / \mathrm{Mn}$ ranges from 2.73 to 4.71 , presumably because of chain transfer reactions due to high reactivity of polymer ends. By employing flow microreactor systems consisting of a T-shaped micromixer and a microtube reactor, however, cationic polymerization using a strong Brønsted acid such as $\mathrm{TfOH}$ can be accomplished in a highly controlled manner without adding a Lewis base (Figure 6) [131]. The polymerization is complete within the residence time of $0.37-1.5 \mathrm{~s}$ at $-25{ }^{\circ} \mathrm{C}$ (almost quantitative yields). The degree of molecular weight distribution control strongly depends on the inner diameter of the mixer and the flow rate as depicted in Table 2. Mw/Mn decreased with a decrease in the mixer inner diameter, presumably because faster mixing is achieved by a mixer of smaller diameter. Mw/Mn also decreases with an increase in the flow rate, probably because the increase of the flow rate enhanced the mixing efficiency. High level of molecular weight distribution control can be attained even at $-25{ }^{\circ} \mathrm{C}$. It is important to note that very low temperatures such as $-78{ }^{\circ} \mathrm{C}$, which might be an obstacle to industrial-scale applications, are not required. 


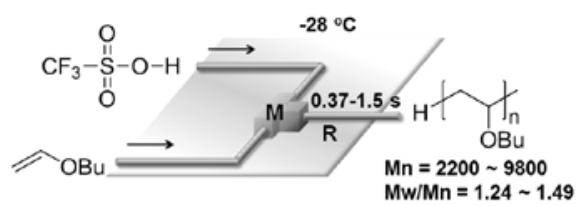

Figure 6 Flow microreactor system for polymerization of vinyl ethers initiated by TfOH. M: T-shaped micromixer; $\mathbf{R}$ : microtube reactor.

Table 2 TfOH initiated polymerization of isobutyl vinyl ether (IBVE) in microreactor system.

\begin{tabular}{ccccc}
\hline $\begin{array}{c}\text { T-shaped inner } \\
\text { diameter } \\
(\mu \mathrm{m})\end{array}$ & \multicolumn{2}{c}{$\begin{array}{c}\text { flow rate } \\
(\mathrm{mL} / \mathrm{min})\end{array}$} & $\mathrm{Mn}^{b}$ & $\mathrm{Mw} / \mathrm{Mn}^{b}$ \\
\cline { 2 - 3 } & $\mathrm{NBVE}$ & $\mathrm{TfOH}$ & & \\
\hline 250 & 2 & 2 & 2900 & 2.30 \\
& 3 & 3 & 2400 & 2.34 \\
& 4 & 4 & 1600 & 1.61 \\
& 5 & 5 & 1500 & 1.22 \\
& 6 & 6 & 1500 & 1.22 \\
500 & 7 & 7 & 1500 & 1.19 \\
& 8 & 8 & 1500 & 1.22 \\
& 5 & 5 & 2000 & 2.54 \\
800 & 6 & 6 & 1500 & 1.82 \\
& 7 & 7 & 1400 & 1.67 \\
& 6 & 6 & 2500 & 2.27 \\
\hline
\end{tabular}

One of the advantages of controlled/living polymerization is that the method allows flexible synthesis of structurally defined block copolymers composed of different monomers, offering greater opportunities for synthesis of organic materials with interesting properties.

An example of microreactor systems for block copolymerization is shown in Figure 7. The first monomer IBVE is mixed with $\mathrm{TfOH}$ in the first micromixer (M1). Introduction of the second monomer (NBVE or EVE) at the second micromixer $\mathbf{M} 2$ results in the formation of the polymer of higher molecular weight with narrow molecular weight distribution [132]. Block copolymerization can be carried out with any combination and with either order of monomer addition as shown in Table 3, demonstrating that the present method serves as a flexible method for the synthesis of block copolymers. Therefore, flow-microreactor-system-controlled polymerization serves as a powerful method for synthesis of structurally well-defined polymers and copolymers in industry. 


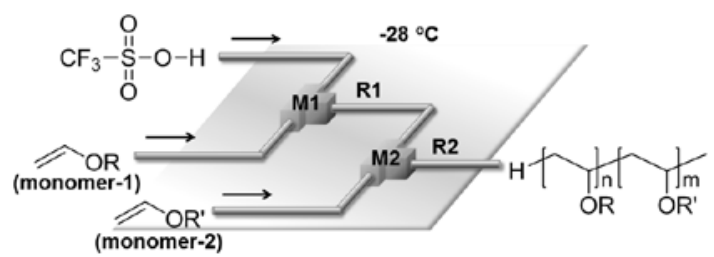

Figure 7 Flow microreactor system for block copolymerization of vinyl ether initiated by TfOH. M1, M2: micromixer; R1, R2: microtube reactor.

Table 3 Block polymerization of vinyl ether initiated by $\mathrm{TfOH}$ using the flow microreactor system.

\begin{tabular}{cccc}
\hline monomer- 1 & monomer- & $\mathrm{Mn}^{b}$ & $\mathrm{Mw}^{b} \mathrm{Mn}^{b}$ \\
\hline IBVE & - & 1500 & 1.18 \\
IBVE & NBVE & 2300 & 1.43 \\
IBVE & EVE & 2400 & 1.54 \\
NBVE & - & 1000 & 1.24 \\
NBVE & IBVE & 1700 & 1.45 \\
NBVE & EVE & 1900 & 1.55 \\
EVE & - & 860 & 1.16 \\
EVE & IBVE & 2100 & 1.54 \\
EVE & NBVE & 2100 & 1.41 \\
\hline
\end{tabular}

\subsubsection{Cationic Polymerization of Diisopropenylbenzenes Using Flow Microreactor Systems}

Polyindanes have received significant research interest because of their remarkable thermal resistance. Extensive work on the synthesis of 1,1,3-trimethyl substituted polyindanes by cationic polymerization of 1,4-diisopropenylbenzenes and their thermal properties has done by Nuyken and coworkers [133, 134]. The polymers of high indane-unit content serve as useful materials having high thermal resistance and low dielectric constants. The use of flow microreactor systems is effective for increasing the indane-unit content. In fact, indane-unit content (99\%) was much higher in the flow microreactor system than that $\mathbf{7 1 \% )}$ for the batch macro system under similar conditions $\left(70{ }^{\circ} \mathrm{C}\right.$, [1,4diisopropenylbenzene] $=0.1 \mathrm{M},[\mathrm{TfOH}]=2 \mathrm{M}$ ) (Figure 8) [135]. The characteristic features of flow microreactor systems including fast mixing and uniformity of the temperature seem to be responsible.

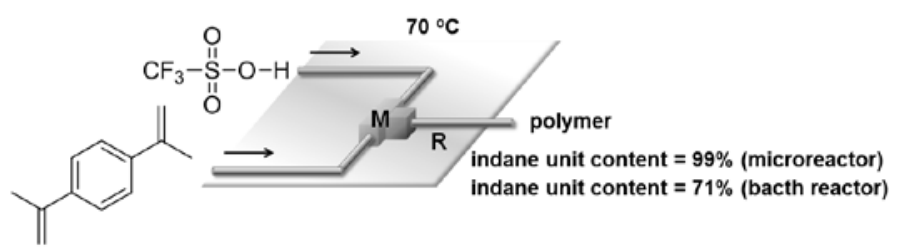


Figure 8 Flow microreactor system for cationic polymerization of 1,4diisopropenylbenzene initiated by TfOH. $\mathbf{M}$ : T-shaped micromixer; R: microtube reactor.

\subsection{Anionic Polymerization}

\subsubsection{Controlled/living Anionic Polymerization of Vinyl Monomers}

Living anionic polymerizations have received significant attentions since Michael Szwarc's first report in the 1950s [136]. Anionic polymerization [137141] serves as an important and powerful method for macromolecular engineering permitting the preparation of highly defined block copolymers, star polymers, and further complex architectures, because the anionic polymer ends are living even in the absence of a capping agent $[142,143]$. In fact, the anionic growing polymer ends (usually organolithium species) can be utilized for end-functionalization reactions with various electrophiles and block copolymerization with other monomers. Major drawbacks of conventional anionic polymerization in polar solvents in batch macro reactors include the requirement of low temperatures, such as $-78^{\circ} \mathrm{C}$ [144]. Such a requirement causes severe limitations in the use of this highly useful polymerization in industry. Using nonpolar solvents, the polymerization can be conducted at higher temperatures, but much longer reaction time is needed for completion. It is also problematic that frequently the use of individually manufactured laboratory equipment is necessary.

The kinetic studies on anionic polymerization in a continuous flow mode have also been reported by Szwarc and Schulz et al [145, 146], and Lochmann and Muller et al [147, 148]. However, preparative anionic polymerizations in continuous flow mode have not been studied until recently.

\subsubsection{Controlled/living Anionic Polymerization of Styrenes}

Anionic polymerization of styrenes is a highly useful technique for the synthesis of polystyrenes with precisely adjustable molecular weights and molecular weight distributions and is applied for the synthesis of structurally welldefined polymers such as end functionalized polymers and block copolymers.

\subsubsection{Controlled/living Anionic Polymerization of Styrenes in Polar Solvent Using Flow Microreactor Systems [149]}

In a conventional anionic polymerization of styrenes in polar solvents in a batch macro reactor, major drawbacks include the requirement of low temperature such as $-78{ }^{\circ} \mathrm{C}$. In contrast, Nagaki and Yoshida reported that controlled anionic polymerization of styrene can be conducted under easily accessible conditions such as $0{ }^{\circ} \mathrm{C}$ in a polar solvent using a flow microreactor to obtain the polystyrene with narrower molecular weight distribution ( $\mathrm{Mn}=1200$ 20000, $\mathrm{Mw} / \mathrm{Mn}=1.09 \sim 1.13$ ) (Figure 9) [150]. Moreover, the molecular weight can be easily controlled by changing the flow rates of monomer and initiator solutions. Furthermore, these methods can be applied to styrene derivatives having silyl, methoxy, alkynyl, and alkylthio groups on the benzene ring. Löwe and Frey also reported the anionic polymerization of styrene at $20{ }^{\circ} \mathrm{C}$ using a flow 
microreactor [151]. Polystyrenes in a broad range of molecular weight with the narrow molecular weight distribution can be obtained within several seconds (Mn $=1700 \sim 70000, \mathrm{Mw} / \mathrm{Mn}=1.09 \sim 1.41$ ). It should be noted that strict dryness of the apparatus and high vacuum techniques is needed in the classical batch methods but that such experimental effort can be significant reduced by using flow microreactors. Residual impurities and moisture can be removed by purging the reactor with solutions of a monomer and an initiator before a solution of a desired polymer product is collected at the outlet of flow microreactors.

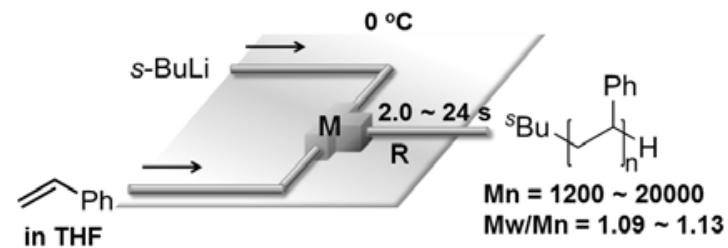

Figure 9 A flow microreactor system for anionic polymerization of styrene in THF. M: T-shaped micromixer; R: microtube reactor.

Integration of chemical reactions enhances the power and speed of organic and polymer synthesis, and recently it has been recognized that flow microreactors enable space-integration of reactions [152-157]. On the basis of livingness of the polymer end, structurally well-defined polymers such as endfunctionalized polymers and block copolymers can be synthesized using integrated flow microreactor systems consisting of two micromixers and two micro tube reactors. For example, functionalization of a living polymer end using chlorosilanes such as chlorotrimethylsilane and chlorodimethylvinylsilane is effectively achieved by using integrated flow microreactor systems to obtain polystyrenes bearing the silyl group at the terminal. Block copolymerization can also be achieved using the integrated flow microreactor system at 0 and $24{ }^{\circ} \mathrm{C}$ to obtain structurally defined block copolymers composed of two different styrenes in quantitative yields (Figure 10).

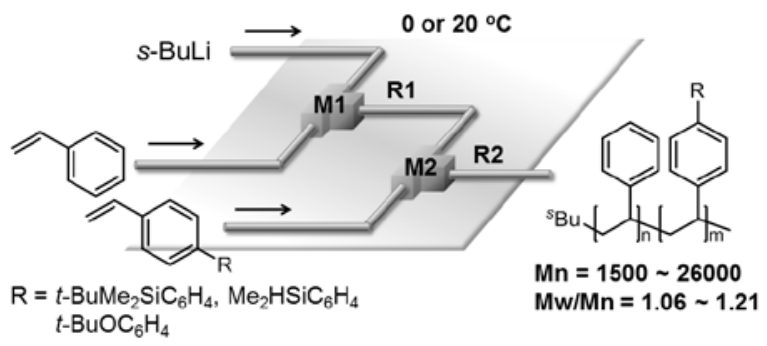

Figure 10 An integrated flow microreactor system for anionic block copolymerization of styrenes in THF. M1, M2: micromixer; R1, R2: microtube reactor. 
End-functionalization with epoxides is also popular, since epoxides high have reactivity toward nucleophiles by virtue of ring strain. Use of functionalized epoxides enables a further transformation after deprotection. For example, polymerization of styrene followed by end-functionalization with the various glycidyl ethers having acetal structures such as ethoxy ethyl glycidyl ether (EEGE), 1,2-isopropylidene glyceryl glycidyl ether (IGG), and trans-2- phenyl1,3-dioxane glycidyl ether (PDGE) can be accomplished using a flow microreactor system (Figure 11) [158]. The acetal and ketal protecting groups in the glycidyl ethers are stable toward the highly reactive carbanionic living polymer ends but they can be easily cleaved under acidic conditions to afford multihydroxyl end-functionalized polymers (Figure 12).

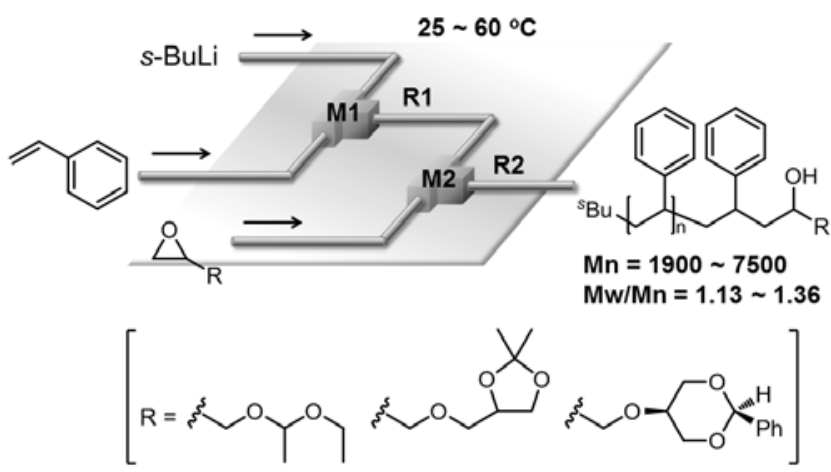

Figure 11 A flow microreactor system for anionic polymerization of styrene in THF initiated by s-BuLi and subsequent functionalization reaction with epoxides. M1, M2: micromixer; R1, R2: microtube reactor.

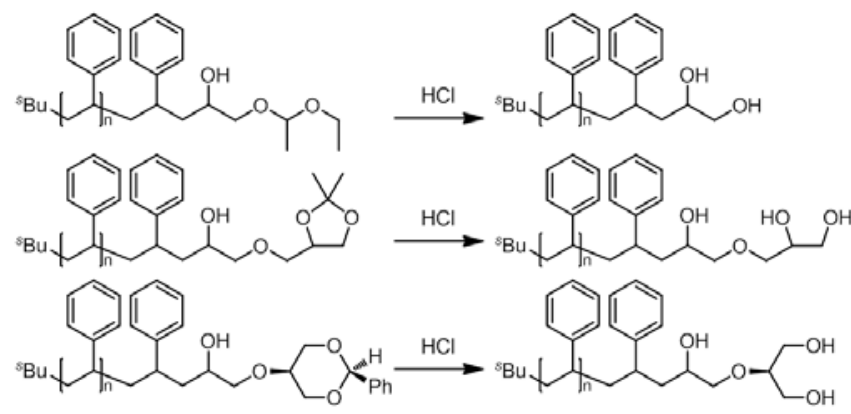

Figure 12 Synthesis of multihydroxyl end-finctionalized polystyrenes

The syntheses of various branched polymers with complex architectures such as star polymers and dendrimer-like star-branched polymers based on living anionic polymerization have been studied extensively. These branched polymers have attracted much attention from theoretical, synthetic, and practical viewpoints 
because of their unique and interesting properties in solution, melt, and solid states. Block copolymers having different polymer chains on a core are especially interesting. To synthesize such a structure, selective 1:1 reaction of a living polymer chain and a poly-functional core molecule is essential in the first step. In a conventional batch macro reactor, an excess amount of poly-functional core should be used to obtain the monosubstituted compound selectively [159-161]. This requirement is problematic because an excess amount of functional core should remain unchanged in the first step, and therefore, it should be removed before proceeding to the second step. The use of a flow microreactor system serves as a powerful method for solving this problem (disguised chemical selectivity [102-113]). As shown in Figure 13, the end functionalization with one equivalent of dichlorodimethylsilane leads to selective formation of a product having a single polymer chain on silicon $(\mathrm{Mn}=1400, \mathrm{Mw} / \mathrm{Mn}=1.13)$, although use of a batch macro reactor leads to lower controllability $(\mathrm{Mn}=1300, \mathrm{Mw} / \mathrm{Mn}=$ 1.21). Extremely fast 1:1 micromixing of the living polymer chain and dichlorodimethylsilane enables the selective introduction of a single polymer chain into silicon. Therefore, the subsequent reaction with another living polymer chain using an integrated flow microreactor system gives block copolymers having two different polymer chains on a silicon core. The chlorosilane having a single polymer chain can be used for the subsequent reaction with alcohols and Grignard reagents.

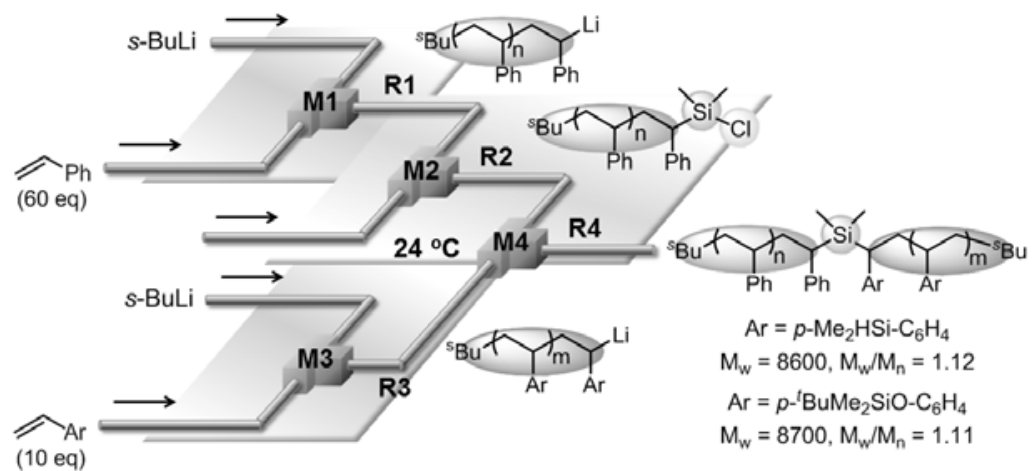

Figure 13 An integrated flow microreactor system for the synthesis of block copolymers having two different polymer chains on a silicon core (M1, M2, M3, M4: T-shaped micromixers; R1, R2, R3, R4: microtube reactors).

\subsubsection{Controlled/living Anionic Polymerization of Styrenes in Nonpolar Solvent Using Flow Microreactor Systems}

Anionic polymerization of styrenes can be conducted in nonpolar solvents at room temperature in a macro batch reactor. However, much longer reaction time is needed for completion. It is also important to carry out the polymerization with $<20 \%$ by volume styrene because the reactions with $>20 \%$ by volume styrene may result in rapid increase in reaction temperature, potentially 
causing danger. The use of flow microreactor is effective for solving the problem. In fact, controlled anionic polymerization of styrene initiated by $s$-BuLi in cyclohexane as a nonpolar solvent can be conducted at $80{ }^{\circ} \mathrm{C}$ by using a flow microreactor system to obtain polystyrenes in quantitative yields within $1 \sim 5 \mathrm{~min}$ (Figure 14). The controlled polymerization of styrene in cyclohexane under high monomer concentration (25 42\%, by volume styrene) at $60{ }^{\circ} \mathrm{C}$ can be achieved by using an aluminium-polyimide microfluidic device (Figure 15) [162]. Moreover, the molecular weight distribution of polymers is influence by the channel patterns ((straight, periodically pinched, obtuse zigzag, and acute zigzag channels).

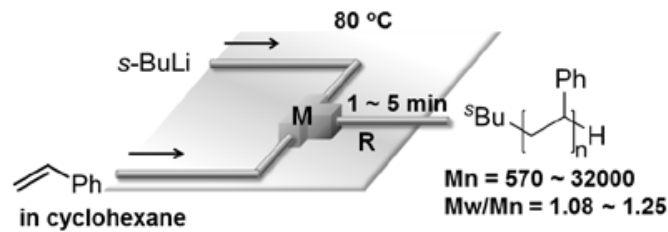

Figure 14 A flow microreactor system for anionic polymerization of styrene in cyclohexane at $80{ }^{\circ} \mathrm{C}$ initiated by s-BuLi. $\mathbf{M}$ : T-shaped micromixer; $\mathbf{R}$ : microtube reactor.

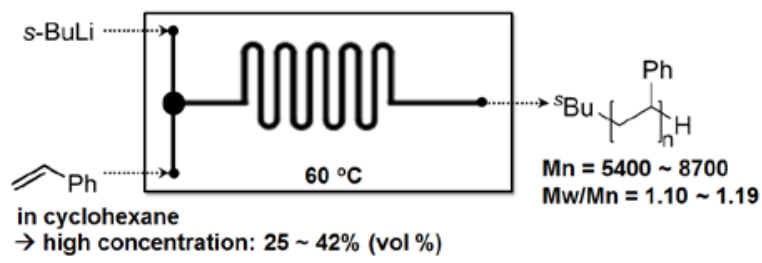

Figure 15 A aluminium-polyimide microfluidic device for anionic polymerization of styrene initiated by s-BuLi in cyclohexane at high concentrations at $60{ }^{\circ} \mathrm{C}$.

\subsubsection{Controlled/living Anionic Polymerization of Alkyl Methacrylates Using Flow Microreactor Systems}

Synthesis of poly(alkyl methacrylate)s with well-defined structures has received significant research interests as versatile materials such as plastics, adhesives and elastomers containing a number of different reactive functions. The use of living anionic polymerization of alkyl methacrylates is very popular for this purpose. Living anionic polymerization of alkyl methacrylates does not need a capping agent, and therefore is very fast compared to living radical polymerization. However, synthesis of poly(alkyl methacrylate)s via anionic polymerization using a conventional batch macro reactor should be carried out at low temperatures such as $-78{ }^{\circ} \mathrm{C}$ to obtain polymers of narrow molecular-weight distribution [163, 164]. The requirement of such low temperatures causes several limitations in the use of this highly useful polymerization in industry. However, if the problem is solved, living anionic polymerization of alkyl methacrylate serves as a powerful method for synthesis of poly(alkyl methacrylate)s. 
Controlled anionic polymerization of alkyl methacrylates initiated by 1,1diphenylhexyllithium using a flow microreactor gives the corresponding poly(alkyl methacrylate)s with high level of control of molecular weight under easily accessible temperatures compared with conventional batch macro polymerization $\left(-28{ }^{\circ} \mathrm{C}\right.$ (methyl methacrylate $\left.(\mathrm{MMA}): \mathrm{Mw} / \mathrm{Mn}=1.16\right), 0{ }^{\circ} \mathrm{C}$ (butyl methacrylate $(\mathrm{BuMA}): \mathrm{Mw} / \mathrm{Mn}=1.24), 24{ }^{\circ} \mathrm{C}$ (tert-butyl methacrylate $(t-$ BuMA): $\mathrm{Mw} / \mathrm{Mn}=1.12)$. Precise control of the reaction temperature and fast mixing of a monomer and an initiator seem to be responsible (Figure 16) [165].

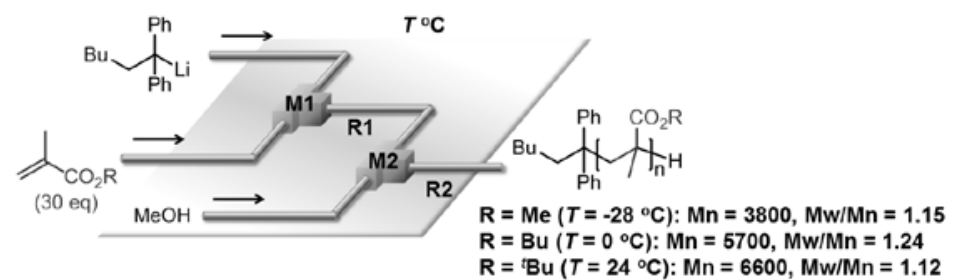

Figure 16 A flow microreactor system for anionic polymerization of alkyl methacrylates initiated by 1,1-diphenylhexyllithium. M1, M2: T-shaped micromixer; R1, R2: microtube reactor.

Livingness of the reactive carbanionic polymer end is important to produce end-functionalized polymers and block copolymers. Livingness of the polymer end in a flow microreactor system can be verified as shown in Figure 17. A solution of an alkyl methacrylate and that of 1,1-diphenylhexyllithium are mixed micromixer M1, and the polymerization is carried out in microtube reactor R1. Then, a solution of the same monomer is introduced at micromixer M2, which is connected to microtube reactor $\mathbf{R} 2$ where the sequential polymerization takes place. By changing the length of R1 with a fixed flow rate, the effect of the residence time in $\mathbf{R} \mathbf{1}$ can be examined. The Mn increases by the addition of the second monomer solution. However, an increase in the residence time in R1 causes an increase in the $\mathrm{Mw} / \mathrm{Mn}$, presumably because of decomposition of the polymer end (Figure 18). By choosing an appropriate residence time in R1 (MMA: 2.95 s, BuMA: $0.825 \mathrm{~s}$ ), the sequential polymerization can be successfully carried out without significant decomposition of the living polymer end [166]. The polymer chain end is really living within such residence times. Moreover, the subsequent reaction of the living polymer end with a different alkyl methacrylate leads to the formation of a block copolymer having narrow molecular-weight distribution (Table 4). 


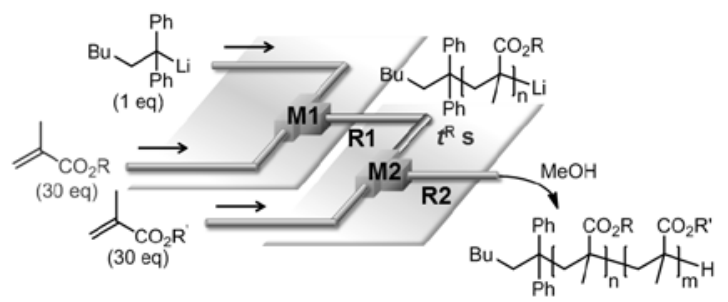

Figure 17 An integrated flow microreactor system for the sequential anionic polymerization of alkyl methacrylates initiated by 1,1-diphenylhexyllithium. M1, M2: T-shaped micromixer; R1, R2: microtube reactor.
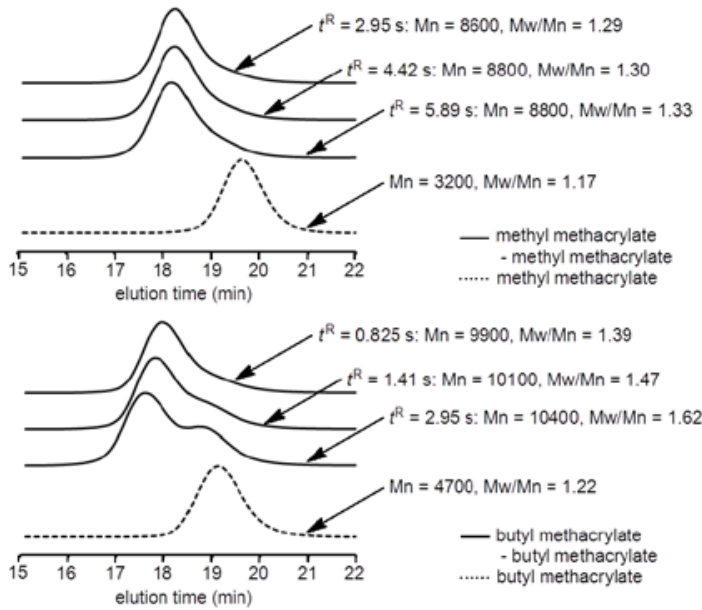

Figure 18 Size exclusion chromatography traces of polymers obtained in the integrated flow microreactor system. Effect of residence time on the molecular weight distribution. (a) methyl methacrylate - methyl methacrylate, (b) butyl methacrylate - butyl methacrylate.

Table 4 Block copolymerization of alkyl methacrylates initiated by 1,1diphenylhexyllithium using the integrated flow microreactor system.

\begin{tabular}{cccc}
\hline monomer-1 & monomer-2 & Mn & Mw/Mn \\
\hline MMA & - & 3200 & 1.17 \\
MMA & MMA & 8600 & 1.29 \\
BuMA & - & 4700 & 1.22 \\
BuMA & BuMA & 9900 & 1.39 \\
BuMA & ${ }^{t}$ BuMA & 9000 & 1.31 \\
${ }^{t}$ BuMA & - & 5300 & 1.13 \\
${ }^{t}$ BuMA & ${ }^{t}$ BuMA & 10000 & 1.13 \\
${ }^{t}$ BuMA & BuMA & 9500 & 1.16 \\
${ }^{t}$ BuMA & MMA & 8400 & 1.15 \\
\hline
\end{tabular}


1.3.4 Controlled/living Anionic Block Copolymerization of Styrenes and Alkyl Methacrylates Using Integrated Flow Microreactor Systems

As mentioned above, flow microreactors are effective for accomplishing the controlled anionic polymerization of styrenes and alkyl methacrylates. A high level of molecular weight distribution control can be achieved under easily accessible conditions such as 24 to $-28{ }^{\circ} \mathrm{C}$ by virtue of the characteristic features of flow microreactors including fast mixing, fast heat transfer, and precise residence time control. Another advantage of flow-microreactor-controlled polymerization is easy modulation of flow microreactors to integrate polymerization reactions. In fact, by using integrated flow microreactor systems, the polystyrene living polymer end, which is produced by butyllithium initiated anionic polymerization of styrene can be effectively trapped with 1,1diphenylethylene, and the resulting organolithium species can be used as a macro initiator for anionic polymerization of alkyl methacrylates. Therefore, styrene alkyl methacrylate diblock copolymers can be synthesized with high level of molecular weight distribution control at easily accessible temperatures such as 24 to $-28{ }^{\circ} \mathrm{C}$ (Figure 19) [167]. Moreover, triblock copolymers can be also synthesized by sequential introduction of styrene and two different alkyl methacrylates in a similar manner (styrene - tert-butyl methacrylate - methyl methacrylate triblock copolymer: $\mathrm{Mn}=8800, \mathrm{Mw} / \mathrm{Mn}=1.23$, styrene - tert-butyl methacrylate - butyl methacrylate triblock copolymer: $\mathrm{Mn}=9000, \mathrm{Mw} / \mathrm{Mn}=$ 1.35).

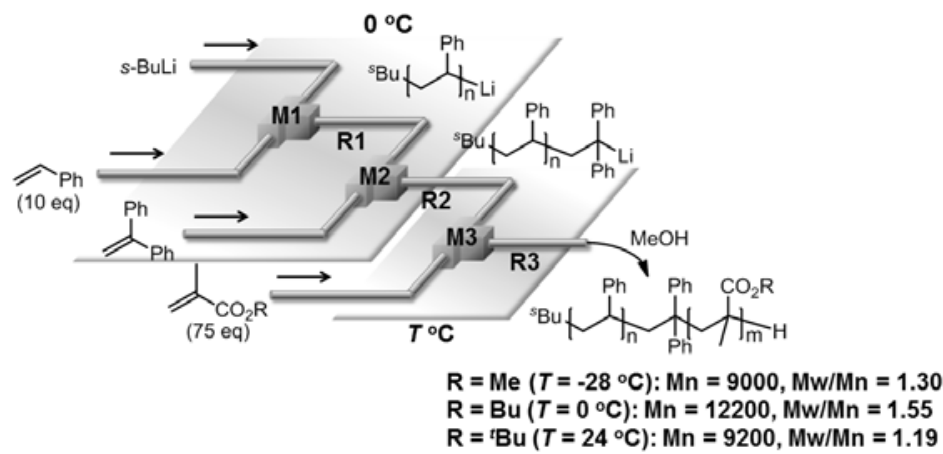

Figure 19 Integrated flow microreactor system for the anionic block copolymerization of styrene and alkyl methacrylates initiated by s-BuLi. M1, M2, M3: T-shaped micromixer; R1, R2, R3: microtube reactor.

\subsection{Radical Polymerization}

\subsubsection{Free Radical Polymerization Using Flow Microreactor Systems}

Free radical polymerization is an important process for the industrial synthesis of macromolecules because free radicals are compatible with a wide variety of functional groups that do not survive in ionic and metal-catalyzed polymerization [168]. Because free-radical polymerization is usually highly 
exothermic, the precise temperature control is essential for performing free radical polymerization in a highly controlled manner. Therefore, the polymerization in a conventional batch macro reactor often suffers from a low level of molecular weight distribution control because of inefficient heat removal and the lack of homogeneity of the reaction temperature. Therefore, the controllability of the reaction temperature is a major concern in free radical polymerization from viewpoint of industrial applications. As a matter of fact, heat removal capacity is often a limiting factor in polymerizations in batch macro reactors. Therefore, the advantage of flow microreactors for radical polymerization is obvious, because they enable fast heat transfer.

Iwasaki and Yoshida reported the free radical polymerization of various monomers using flow microreactor systems. Polymerization of butyl acrylate (BA) gives the polymer of much smaller $\mathrm{Mw} / \mathrm{Mn}$ than that obtained with batch macro reactor because of a much higher heat-removal efficiency of the flow microreactor (Figure 20) [169]. For the polymerization of benzyl methacrylate ( $n$ BMA) and methyl methacrylate (MMA), the effect of the flow microreactor on molecular weight distribution control is smaller than the case of BA. For the polymerization of vinyl benzoate $(\mathrm{VBz})$ and styrene, no appreciable effect is observed. The tendency indicates that the flow microreactor is quite effective for highly exothermic polymerization such as that of BA, but it is not so effective for less exothermic polymerization. Similar results on the polymerization of styrene have been reported by Leveson et al [170]. Moreover, a microchemical pilot plant for radical polymerization of MMA has been built by numbering up eight microtube reactors (vide infra) [171].
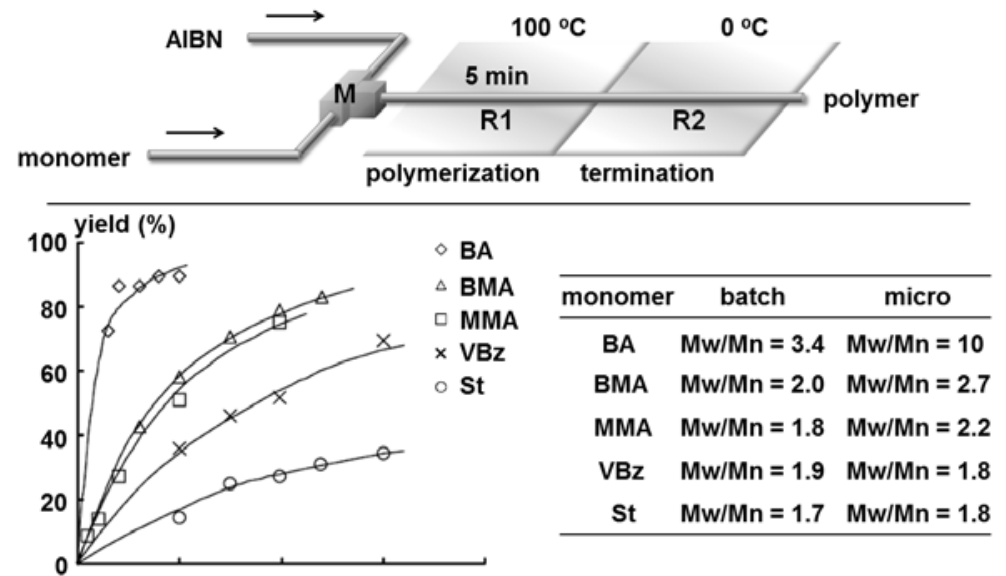

Figure 20 A flow microreactor system for the free radical polymerization initiated by AIBN and relative rate of the polymerization in the flow microreactor. $\mathbf{M}$ : Tshaped micromixer; R1, R2: microtube reactor. 
Effects of mixing in radical polymerization of methyl methacrylate are interesting [172]. The use of $5 \mathrm{~mm}$ static mixer leads to fouling in the reactor. In contrast, the use of IMM micromixer with 36 lamellae of $25 \mu \mathrm{m}$ thickness results in the reduction of the fouling. The numbering-up approach enables production of 2000 tons per year without the fouling problem [173].

Serra et al. studied the outstanding effect of mixing on conversion, molecular weight and polydispersity in free radical polymerizations of styrene by a numerical simulation using different micromixer geometries [174,175].

Latex production by miniemulsion polymerizations [176-178] in continuous tubular reactors has also been reported by McKenna et al [179].

\subsubsection{Living Radical Polymerization Using Flow Microreactor Systems}

The major drawback of free radical polymerization is the low controllability of macromolecular structures, and the polymers have broad molecular weight distribution. Living radical polymerization [180-184] has been developed to overcome the problem. Because more than $50 \%$ of polymers are produced via free radical processes in industry, living radical polymerization offers a possible solution to synthesizing polymers of narrow molecular weight distribution [185]. Various methods including the atom transfer radical polymerization (ATRP) [186-191], the reversible addition-fragmentation chain transfer radical polymerization (RAFT) [192-194], the nitroxide-mediated radical polymerization (NMP) [195-197], organoiodine-mediated radical polymerization (IRP) [198], cobalt-mediated polymerization [199] and organotellurium-, antimony-, or bismuth-mediated living radical polymerization (TERP) [200-205] have been developed for conducting living radical polymerization.

\subsubsection{Atom Transfer Radical Polymerization (ATRP) Using Flow Microreactor Systems}

Atom transfer radical polymerization (ATRP) [186-191] is one of the most extensively studied living radical polymerization because of its simplicity and broad applicability, and serves as a method for synthesizing previously inaccessible well-defined nanostructured polymeric materials [206]. One of the main drawbacks is low catalytic efficiency and deep color of the final product. In general, the use of $0.1 \% \sim 1 \%$ catalyst results in the formation of the colored polymer containing the residual catalyst. Therefore, after polymerization, additional purification by passing the solution through silica- or alumina-gel is needed to remove the catalyst from product. A possible solution to this problem is the use of supported catalysts.

A continuous column reactor packed with silica-gel supported $\mathrm{CuBr}$ HMTETA catalyst for ATRP of methyl methacrylate (MMA) exhibits high catalyst retention, high catalytic activity, and good stability up to $100 \mathrm{~h}$ (Figure 21). Moreover, the product solution is colorless [207]. In addition, the molecular weight of the resulting PMMA can be controlled by simply changing the flow rate of MMA. The polymerization in the reactor is in first order with respect to 
monomer concentration, typical for ATRP process. However, the polydispercity index of the resulting polymer is about 1.8, which is larger than that for the polymer prepared using the same supported catalyst in batch (about 1.1). This is presumably because back-mixing in the column and trapping of polymer chains in the silica gel pores take place. The system in which two column reactors are connected in series has been developed and is applied to block copolymerization of MMA with n-butyl methacrylate (nBMA) (Figure 22) [208].

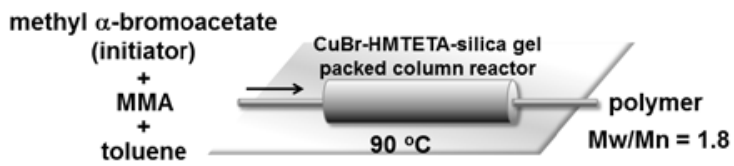

Figure $21 \mathrm{CuBr}-\mathrm{HMTETA}$-silica gel packed column reactor for the atom transfer radical polymerization of MMA initiated by methyl $\alpha$-bromoacetate.

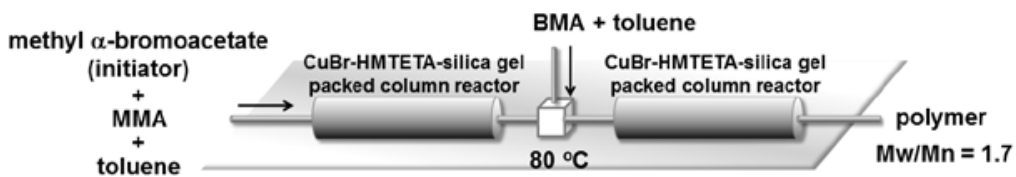

Figure $22 \mathrm{CuBr}$-HMTETA-silica gel packed column reactor for the atom transfer radical block copolymerization of MMA with butyl methacrylate (nBMA) initiated by methyl $\alpha$-bromoacetate.

Photopolymerized microfluidic device consisting of two inlets, active mixing chamber containing a magnetic stir bar, a single reaction channel (500 $\times$ $600 \mu \mathrm{m})$, and one outlet has been used for ATRP reaction of 2-hydroxypropyl methacrylate (HPMA) initiated by methyl 2-bromopropionate (Figure 23) [209]. The molecular weight can be controlled by changing the residence time at the different flow rates (Table 5). The kinetics and polymer properties are similar to those for the batch reactions reported in the literature [210]. Furthermore, a block copolymer poly(ethylene oxide-block-2-hydroxypropyl methacrylate) (PEO-bPHPMA) can be prepared by the copolymerization of HPMA with a PEO macroinitiator prepared by reaction of the terminal hydroxy group of the PEO-OH with a two-fold molar excess of 2-bromoisobutyryl bromide and triethylamine (Figure 24). The stoichiometry of the reactants can be easily changed by varying relative flow rates [211].

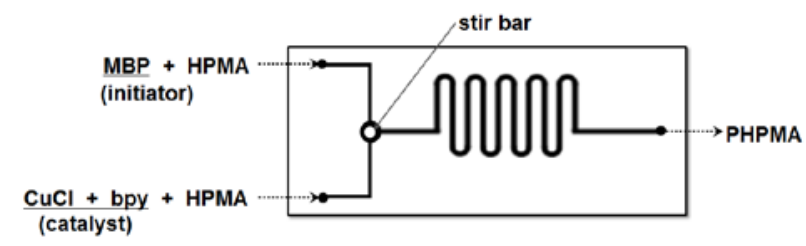


Figure 23 A microfluidic device for the synthesis of poly(2-hydroxypropyl methacrylate) (PHPMA) using a MBP initiator.

Table 5 Microchannel polymerization of HPMA at different pumping rates and initiator concentrations.

\begin{tabular}{cccccc}
\hline$[\mathrm{MBP}] /[\mathrm{HPMA}]$ & $\begin{array}{c}\text { pump rate } \\
(\mu \mathrm{l} / \mathrm{h})\end{array}$ & $\begin{array}{c}\text { residence time } \\
(\mathrm{h})\end{array}$ & $\begin{array}{c}\text { conv. } \\
(\%)\end{array}$ & Mn & Mw/Mn \\
\hline $1: 40$ & 50 & 2.00 & 92 & 6240 & 1.21 \\
& 150 & 0.67 & 74 & 5560 & 1.19 \\
& 300 & 0.33 & 47 & 3950 & 1.26 \\
& 400 & 0.25 & 29 & 3300 & 1.27 \\
$1: 100$ & 500 & 0.20 & 17 & 2770 & 1.32 \\
& 50 & 2.00 & 62 & 12740 & 1.26 \\
\hline
\end{tabular}

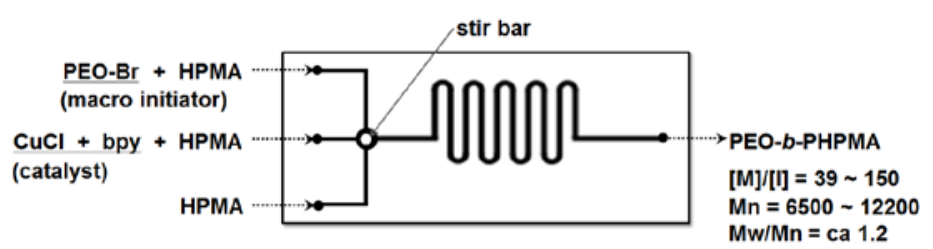

Figure 24 A microfluidic device for the synthesis of poly(ethylene oxide-block-2hydroxypropyl methacrylate) (PEO-b-PHPMA) using a PEO macroinitiator.

\subsubsection{Reversible Addition-fragmentation Chain Transfer Radical (RAFT) Polymerization Using Flow Microreactor Systems}

Reversible addition-fragmentation chain transfer radical polymerization (RAFT) [192-194] is known for its compatibility with a wide range of monomers, temperature, and impurities, as compared to other living radical polymerizations such as ATRP and NMP.

RAFT polymerization in miniemulsion has been carried out in a tubular reactor. Emulsion is prepared in a batch reactor using sodium dodecyl sulfate (SDS, surfactant), Triton X-405 (surfactant), styrene (monomer), hexadecane (costabilizer), and 1-phenylethyl phenyldithioacetate (PEPDTA, RAFT agent),and is pumped into a continuous sonication vessel to obtain miniemulsion (Figure 25) [212]. The miniemulsion is introduced to tube reactors where the polymerization takes place. The polymerization in the tube reactor behaved kinetically similar to the batch polymerization. However, the tubular reactor produces polymer with a slightly higher molecular weight distribution than that for the polymer produced in a batch reactor, presumably because back-mixing or axial dispersion effects in the tubular reactor that would broaden the residence time distribution of particles within the reactor. The present systems can be extended for the synthesis of block copolymer of polystyrene and poly(butyl acrylate) [213]. 


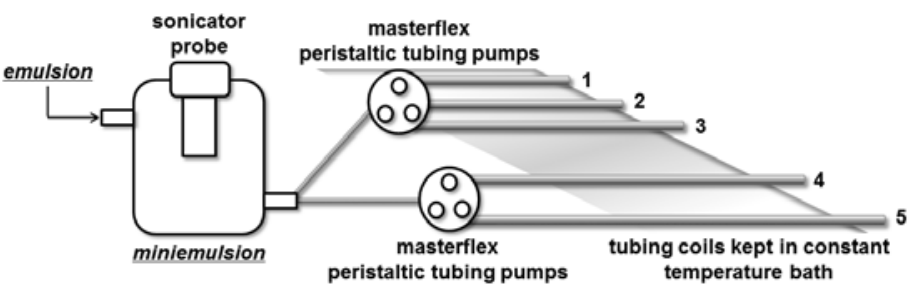

Figure 25 A multi-tubule reactor for RAFT polymerizations using continuous miniemulsion.

RAFT polymerizations of $\mathrm{N}$-isopropylacrylamide (NIPAM) as monomer and a trithiocarbonate as chain transfer agent has been carried out using a flow microreactor under homogeneous conditions (Figure 26) [214]. In flow process, an increase in the inner diameter of the tube results in slightly lower conversions and wider molecular weight distributions. Polymerization rates in a flow microreactor are considerably higher in comparison with those of batch polymerization because of uniform heating (Table 6).

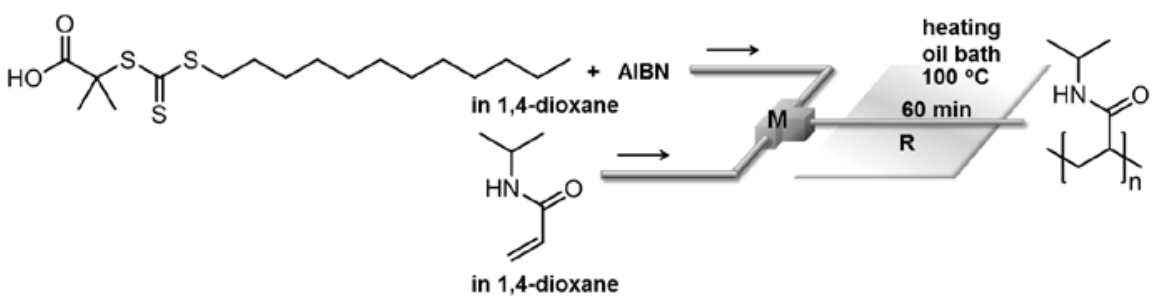

Figure 26 A continuous flow reactor for the reversible addition-fragmentation chain transfer radical polymerization. M: micromixer; R: microtube reactor.

Table 6 Conversion of the RAFT polymerization and poly(nisopropylacrylamide)(PNIPAM) properties after $60 \mathrm{~min}$ at $90^{\circ} \mathrm{C}$.

\begin{tabular}{ccccc}
\hline method & heating method & conversion (\%) & $\mathrm{Mn}$ & $\mathrm{Mw} / \mathrm{Mn}$ \\
\hline flow & oil bath & 88 & 21500 & 1.15 \\
flow & oil bath & 78 & 17200 & 1.31 \\
flow & oil bath & 79 & 20000 & 1.31 \\
batch & oil bath & 40 & 13400 & 1.12 \\
batch & microwave & 85 & 19400 & 1.16 \\
\hline
\end{tabular}

Then, RAFT polymerizations of various monomers including acrylamides, acrylates, and vinyl acetate has been studied by Hornung at al [215]. Polymers of narrow molecular weight distribution and average molecular weights similar to those of batch polymerizations are obtained on a multigram scale.

\subsubsection{Nitroxide-mediated Radical Polymerization (NMP) Using Flow Microreactor Systems}


Nitroxide-mediated radical polymerization (NMP) [195-197] can be applied to a wider range of monomers such as styrenes, acrylates, acrylamides, acrylonitrile, and 1,3-dienes. Acyclic nitroxides such as 2,2,5-trimethyl-4-phenyl3-azahexane-3-nitroxide (TIPNO) or $N$-tert-butyl- $N$-(1-diethyl phosphono-2,2dimethylpropyl) nitroxide (DEPN) enables the reversible termination of the growing polymer chains.

Nitroxide-mediated radical polymerization (NMP) of styrene and $n$-butyl acrylate at $140{ }^{\circ} \mathrm{C}$ has been performed in a continuous-flow microtubular reactor (Figure 27) consisting of a stainless steel tube reactor and a back pressure cartridge [216]. In the case of styrene polymerization, there is no difference between batch reactors and flow microreactors. However, for $n$-butyl acrylate, a better control of the polymerization has been observed in the flow microreactor $(\mathrm{Mw} / \mathrm{Mn}=1.80$ (batch reactor), $\mathrm{Mw} / \mathrm{Mn}=1.44$ (flow microreactor)). Moreover, consumption of the monomer is much faster using the flow microreactor (Figure 28).

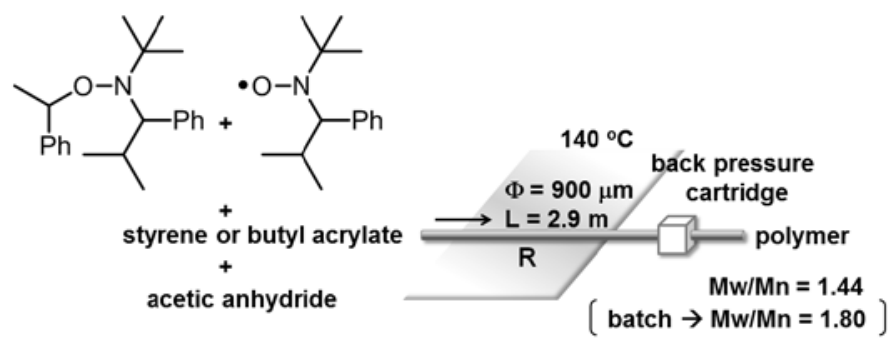

Figure 27 A continuous flow microreactor system for nitroxide-mediated radical polymerization (NMP) of poly(styrene) or poly( $n$-butyl acrylate). R: microtube reactor.

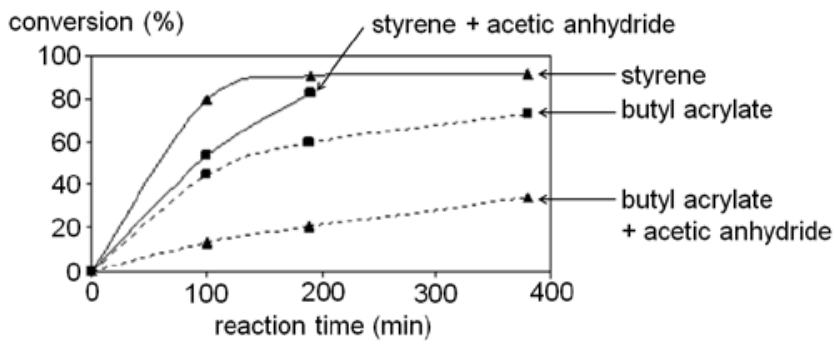

Figure 28 Conversion vs residence time of nitroxide-mediated radical polymerization of styrene and $n$-butyl acrylate without or with acetic anhydride.

Nitroxide-mediated radical polymerization of styrene in a miniemulsion can be also performed in a tubular reactor [217]. In the first step, a macroinitiator is prepared by bulk polymerization in a batch reactor and the subsequent miniemulsion polymerization is carried out in a tubular reactor. The 
polymerization kinetics in the tubular reactor is similar to those in a batch reactor. It is also noteworthy that both the preparation of a macroinitiator and miniemulsion polymerization can be achieved in a continuous tubular reactor to obtain polystyrene-block-poly(butyl acrylate) diblock and polystyrene-blockpoly(butyl acrylate)-block polystyrene triblock copolymers [218].

Continuous nitroxide-mediated block copolymerization of $n$-butyl acrylate (first monomer) and styrene (second monomer) can be performed using two serial $900 \mu \mathrm{m}$ inner diameter stainless steel microtube reactors (Figure 29) [219]. For the second polymerization process, the influence of mixing was examined by changing micromixers. The use of a high pressure interdigital multilamination micromixer (HPIMM) provided by the IMM (Mainz, Germany)), can significantly reduce the polydispersity index $\left(\mathrm{Mw} / \mathrm{Mn}=1.36,120{ }^{\circ} \mathrm{C}\right)$ compared with that obtained in a batch macro reactor $\left(\mathrm{Mw} / \mathrm{Mn}=1.74,120{ }^{\circ} \mathrm{C}\right)$. Efficient mixing of a viscous solution of poly( $n$-butyl acrylate) and a solution of styrene by virtue of small diffusion paths caused by small lamination widths seems to be responsible. Conversions, molecular weights, and molecular weight distributions are significantly influenced by the nature of micromixers [220]. The results obtained with three micromixers, i.e. two HPIMMs with different lamination widths and a slit plate micromixer (LH2) manifactured by Ehrfeld Mikrotechnik BTS (Wendelsheim, Germany) are summarized in Table 7. Molecular weight distribution and molecular weight strongly depend on the factor $\mathrm{F}\left(F=1 / N\left(W_{C}+W_{L}\right)\left(N\right.\right.$ : number of channels per inlet, $W_{C}$ : channel width, $W_{L}$ : slit or aperture width)). The relationship between molecular weight distribution or molecular weight and $\mathrm{F}$ is linear, enabling prediction of copolymer features.

Table 7 Interdigital multilamination micromixer characteristics

\begin{tabular}{cccc}
\hline micromixer & HPIMM & HPIMM & LH2 \\
\hline & ML45 & ML20 & ML50 \\
\hline number of channels per inlet $N$ & 16 & 15 & 10 \\
channel width $W_{C} / \mu \mathrm{m}$ & 45 & 20 & 50 \\
microstructure thickness $/ \mu \mathrm{m}$ & 250 & 100 & 300 \\
Slit or aperture width $W_{L} / \mu \mathrm{m}$ & 60 & 60 & 50 \\
Form factor $F / \mathrm{mm}^{-1}$ & 0.59 & 0.83 & 1.0 \\
\hline
\end{tabular}




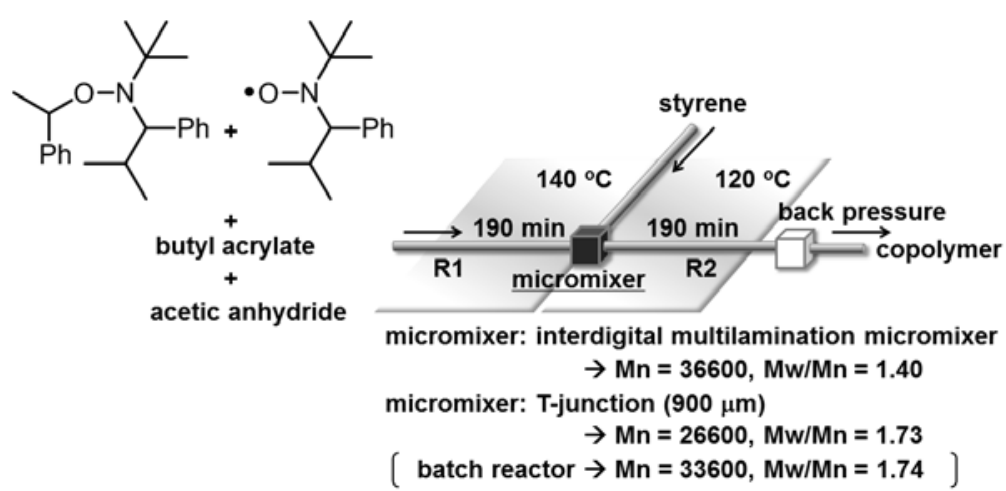

Figure 29 A continuous flow microreactor system for nitroxide-mediated radical block copolymerization of $n$-butyl acrylate and styrene. R1, R2: microtube reactor.

Very recently, Ryu and Studer et al. also reported the use of highly sterically hindered amines [221,222] for the nitroxide-mediated radical block copolymerization (NMP) of styrene and butyl acrylate in a flow microreactor [223]. The polymerization in the flow microreactor is faster than that in the batch system, although polymers with slightly smaller molecular are obtained in flow.

In general, gel permeation chromatography (GPC) is used to characterized polymers. However, sample preparation and analysis requires long time. The integration of a flow microreactor with analytical devices to monitor the progress of polymerization in real time allows fast screening and optimization. For example, the continuous online rapid size-exclusion chromatography monitoring of polymerizations (CORSEMP) system has been developed by Serra and Hadziioannou et al [224]. It consists of automatic samplings, dilutions, and injections every 12 min of polymers synthesized in continuous flow (Figure 30). In addition, this system also includes a viscometer, RI and UV detectors, and a GPC to determine the molecular weights and molecular weight distributions. The nitroxide-mediated block copolymerization of $n$-butyl acrylate and styrene can be monitored 'near real-time' with good accuracy and repeatability. Very recently, bifurcation analysis and grade transition dynamic optimization for NMP of styrene in a tubular reactor have been demonstrated by Flores-Tlacuahuac et al [225, 226]. 


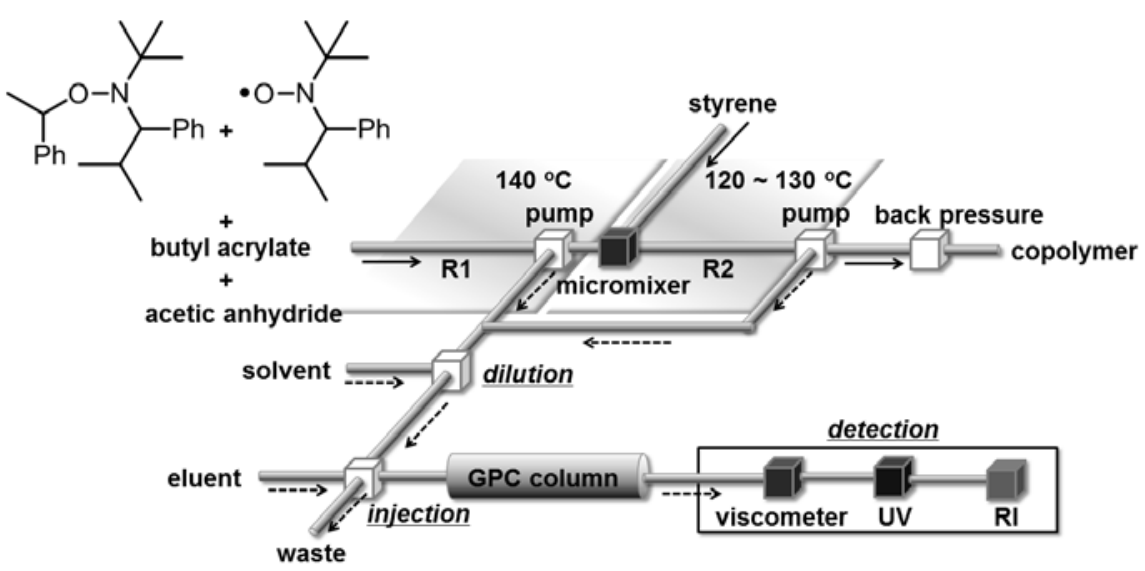

Figure 30 The continuous online rapid size-exclusion chromatography monitoring of polymerizations (CORSEMP) system for nitroxide-mediated radical block copolymerization of $n$-butyl acrylate and styrene.

\subsection{Ring Opening Polymerization Using Flow Microreactor Systems}

Ring-opening polymerization is categorized into chain-growth polymerization, in which the terminal end of a polymer acts as a reactive center [227]. The reaction of cyclic compounds with a polymer end causes the cleavage of the ring and repeating of this process lead to the formation of high-molecularweight polymers. The synthesis of polyamides from lactams, polyesters from lactones, and polyethers from cyclic ethers has been widely used.

The most popular approach for the synthesis of polyamides from amino acids [228] is an amino acid $N$-carboxyanhydride (NCA) method (Figure 31) [229]. The initiation with a base such as tertiary amine followed by the reaction of another NCA molecule with the resulting activated NCA anion produces a dimer with an electrophilic $N$-acyl NCA end group and a nucleophilic carbamate group. Then, $\mathrm{N}$-carbamic acid is detached as carbon dioxide during the propagation reaction. It is known that deprotonation of NCA and the attack of NCA anion are relatively fast [230]. Therefore, it is important to control these steps. However, in conventional batch systems, the polymerization control would be difficult due to local gradients of the concentrations. In contrast, flow microreactor systems enable such control (Figure 32) [231]. For example, polymerization of $\mathrm{N}$ benzyloxycarbonyl-L-lysine using a flow microreactor system consisting of a polydimethylsiloxane-based multi-lamination mixer and a PTFE microtube leads to narrower molecular weight distribution (flow: $\mathrm{Mw} / \mathrm{Mn}=$ ca 1.2, batch: $\mathrm{Mw} / \mathrm{Mn}$ = 1.5), although molecular weights are similar (flow $\mathrm{Mn}=$ ca. 20,000, batch: $\mathrm{Mn}=$ ca. 18,000) [232]. The use of a simple T-shaped connector as a mixer leads to broader molecular weight distribution, indicating the importance of fast micromixing. The present flow microreactor system can be applied to polymerization and copolymerization of other amino acid NCAs to obtain 
poly(Glu), copoly(Lys, Ala) and copoly(Lys, Leu) of narrower molecular weight distribution than those obtained from the batch reactor (Table 8).

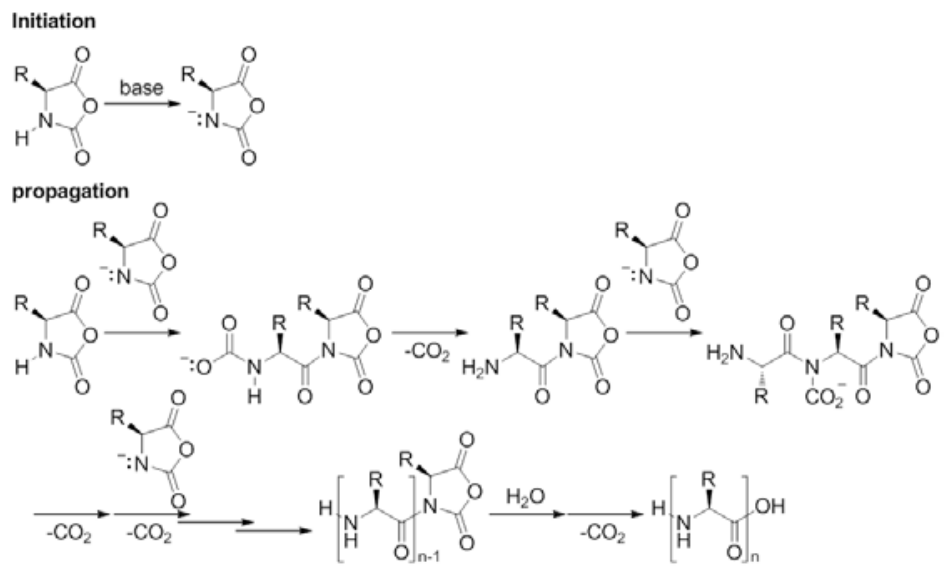

Figure 31 Mechanism of polymerization of amino acid $N$-carboxyanhydride (NCA) initiated by a base.

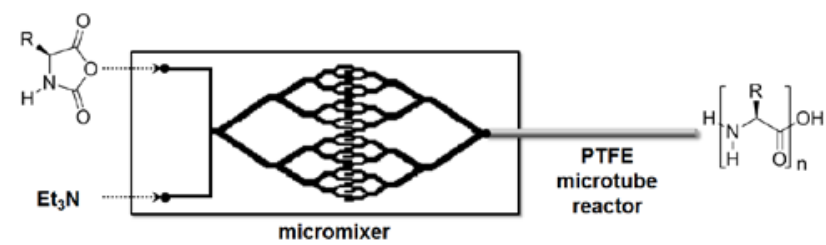

Figure 32 A flow microreactor system consisting of a polydimethylsiloxane (PDMS) multi-layered laminar micromixer and PTFE microtubes for polymerization of amino acid $N$-carboxyanhydride (NCA) initiated by triethylamine.

Table 8 Comparison of polymer properties.

\begin{tabular}{cccc}
\hline polymer & & Mn & Mw/Mn \\
\hline Poly(Glu) & batch & 40200 & 1.56 \\
& microreactor & 40000 & 1.17 \\
Poly(Lys, Ala) & batch & 17700 & 2.56 \\
& microreactor & 18800 & 1.64 \\
Poly(Lys, Leu) & batch & 18100 & 2.13 \\
& microreactor & 19200 & 1.54 \\
\hline
\end{tabular}

A silicon-glass based flow microreactor system that is suitable for long periods of use has been developed and applied to the polymerization of amino acid NCAs [233]. The flow microreactor exhibits excellent controllability of the molecular weight distribution. Moreover, a single flow microreactor can produce 
$100 \mathrm{mg} / \mathrm{min}$ of poly(Lys/Leu). It means that more than $200 \mathrm{~g}$ of poly(Lys/Leu) acids can be produced in 2 months.

Hyperbranched polymers have attracted much attention because these polymers exhibit different characteristic features, such as a lower viscosity, higher solubility, and higher amount of terminal groups, compared with those of the corresponding linear polymers. Such polymers can be prepared by ring-opening multibranching polymerization. Hyperbranched polyglycerols are popular because they have a large number of hydroxyl groups and exhibit excellent biocompatibility [234]. Continuous micromixer-assisted flow process for the synthesis of hyperbranched polyglycerol by ring-opening multibranching polymerization of glycidol was demonstrated by Wilms et al (Figure 33) [235]. The polymerization was carried out in the presence of trimethylol propane (TMP) as a multifunctional initiator and potassium methoxide necessary to deprotonation $10 \%$ of the hydroxyl groups to obtain well-defined hyperbranched polyglycerol with molecular weights up to $1,000 \mathrm{~g} / \mathrm{mol}$. However, higher flow rates results in the partial formation of high molecular weight probably because of the formation of "hot spots" where the polymerization proceeds much faster.

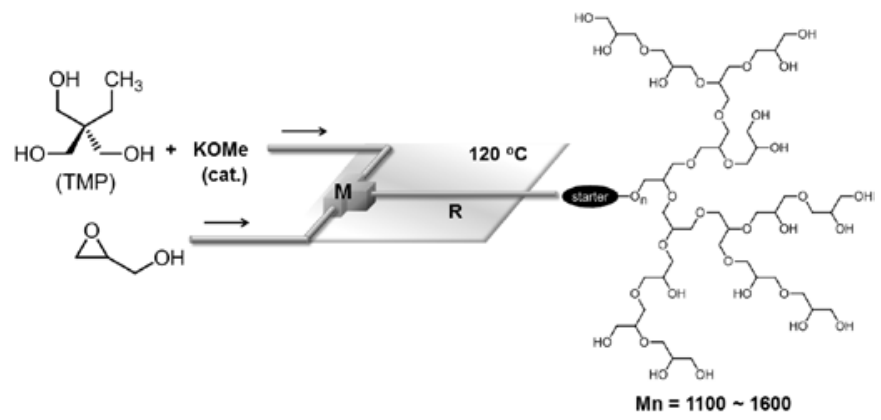

Figure 33 A flow microreactor for synthesis of hyperbranched polyglycerol by ring-opening multibranching polymerization of glycidol. $\mathbf{M}$ : micromixer.

The continuous-flow microwave-assisted polymerization of 2-ethyl-2oxazoline was reported by Schubert et al [236]. The flow process overcomes the problems associated with scale-up of the batch process including safety issues.

\subsection{Polycondensation Using Flow Microreactor Systems}

Polycondensation reactions are important processes for the synthesis of polyesters, polycarbonates, polyamides, and polysiloxanes [237]. Polycondensation reaction is classified into a step-growth polymerization, which involves a stepwise covalent-bond-forming reaction between functional groups of two monomers, between a functional group of a monomer and a polymer end, or between functional groups of two polymer ends. Because the propagating polymers and monomer do not contain an active species, such as cations, radicals, or anions, the polymer chains reach moderately high molecular weight even at 
very high conversion. Therefore, in principle, it is difficult to control molecular weight and molecular weight distributions precisely.

Polycondensation of 4,4'-oxydianiline (ODA) and isophthaloyl dichloride (IPA) followed by terminal modification has been carried out in a flow microreactor system (Figure 34) [238]. The polymerization in the flow microreactor is faster than that in the batch system. A higher mixing efficiency of monomer seems to be responsible for the faster reaction. It is also important to note that the molecular weight distribution of the polymer obtained in the flow is slightly narrower than that obtained in batch. Precise control of reaction temperature in the microreactor seems to be responsible.

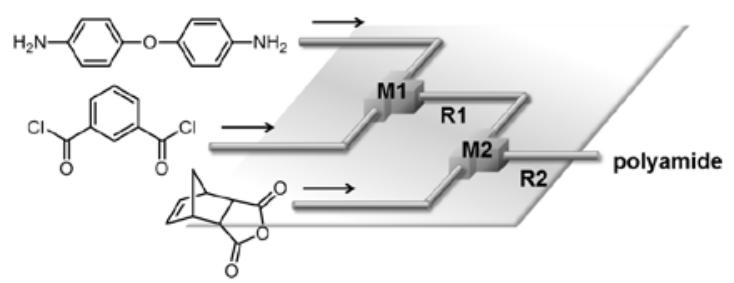

Figure 34 A flow microreactor system for polycondensation of 4,4'-oxydianiline (ODA) and isophthaloyl dichloride (IPA) followed by terminal modification. M1, M2: micromixer; R1, R2: microtube reactor.

Dendrimers, which have highly branched 3D structure provide a high degree of surface functionality and versatility. Polycondensation reactions are widely used for synthesizing various dendrimers. The synthesis of polyamide dendrons (G1 Dendron, G2 Dendron) and a dendrimer (G1 Dendrimer) as shown in Figure 35 has been carried out using flow microreactors [239]. The use of flow microreactors enables significant reduction of reaction time. In addition, the reaction can be performed at a constant temperature such as $30{ }^{\circ} \mathrm{C}$ in flow, whereas low temperature such as $0{ }^{\circ} \mathrm{C}$ is necessary for the first mixing to avoid side reactions in batch. Moreover, polyamide dendrons can be deposited onto the functionalized glass surface through amide bond formation in flow. 


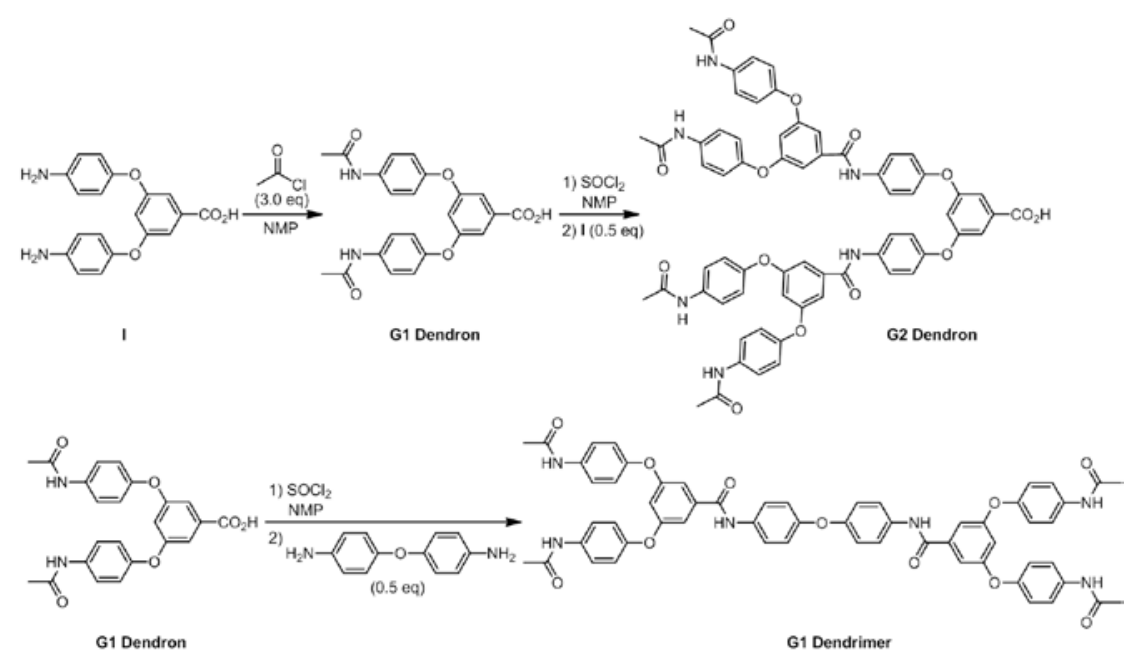

Figure 35 Reactions of the convergent synthesis of polyamide dendrons and dendrimers.

By polycondensation of trifunctional silanols, poly(silsesquioxane)s, which emerge as materials for various applications ranging from low dielectric constant materials [240] to flame-retardant material [241], can be prepared. The polycondensation reaction of methyltrimethoxysilane (MTMS) and various trimethoxysilanes involving $p$-(chlormethyl)phenylethyltrimethoxysilane (1), dithiobenzoic acid benzyl-(4-ethyltrimethoxysilyl) ester (2), dithiobenzoic acid 1ethylphenyl-4-(ethyltrimethoxysilyl) ester (3) and $N, N$ diethyldithiocarbamoylethylphenyl(trimethoxy)silane (4) [242, 243] can be successfully achieved in a microreactor to obtain corresponding poly(silsesquioxane)s (Figure 36) [244]. The yields are significantly higher than those in batch. The polydispersity indexes can be smaller than 2, whereas they are usually between 2.2 and 3 in batch. Moreover, molecular weights, which range from $\mathrm{Mn}=1900$ to 11000 , can be controlled by changing the residence time (Table 9).

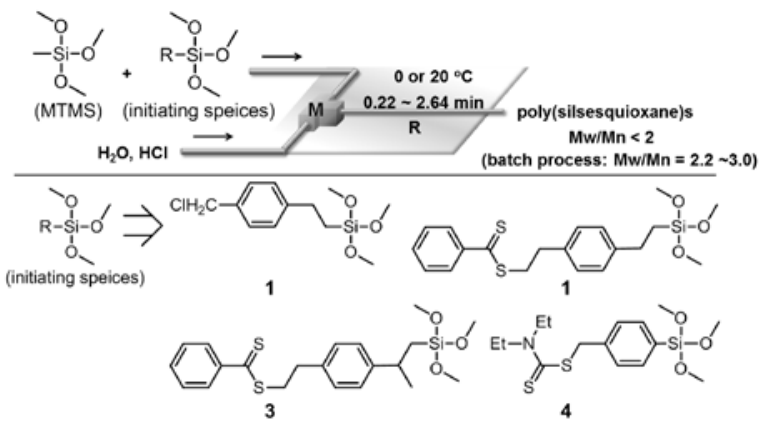


Figure 36 A flow microreactor system for polycondensation reactions of trialkoxysilanes. M: micromixer; R: microtube reactor.

Table 9 Molecular weight and molecular weight distribution obtained in microreactor synthesis.

\begin{tabular}{ccccc}
\hline initiator & temperature $\left({ }^{\circ} \mathrm{C}\right)$ & residence time $(\mathrm{min})$ & $\mathrm{Mn}$ & $\mathrm{Mw} / \mathrm{Mn}$ \\
\hline $\mathbf{1}$ & 0 & 0.22 & 1900 & 1.47 \\
& 0 & 0.66 & 3450 & 1.49 \\
& 0 & 1.32 & 4350 & 1.50 \\
& 0 & 1.98 & 6250 & 1.54 \\
$\mathbf{1}$ & 0 & 2.64 & 8400 & 1.59 \\
& 20 & 0.22 & 2700 & 1.71 \\
$\mathbf{2}$ & 20 & 2.64 & 9550 & 1.93 \\
& 0 & 0.22 & 2100 & 1.46 \\
$\mathbf{2}$ & 0 & 2.64 & 8200 & 1.69 \\
& 20 & 0.22 & 3200 & 1.79 \\
$\mathbf{3}$ & 20 & 2.64 & 9700 & 1.87 \\
& 0 & 0.22 & 2200 & 1.53 \\
$\mathbf{3}$ & 0 & 2.64 & 8900 & 1.65 \\
& 20 & 0.22 & 3400 & 1.71 \\
$\mathbf{4}$ & 20 & 2.64 & 10100 & 1.92 \\
$\mathbf{4}$ & 0 & 0.22 & 2250 & 1.39 \\
& 0 & 2.64 & 8100 & 1.61 \\
& 20 & 0.22 & 3700 & 1.87 \\
& 20 & 2.64 & 11000 & 1.95 \\
\hline
\end{tabular}

\subsection{Ziegler-Natta polymerization Using Flow Microreactor Systems}

Ziegler-Natta polymerization [245, 246] is an important method of vinyl polymerization because it allows us to make polymers of specific tacticity. As reported by Santos and Metzger, Ziegler-Natta polymerization can be carried out in a flow microreactor system coupled directly to the ESI source of a Q-TOF mass spectrometer (Figure 37) [247]. In the first micromixer M1, a catalyst $\left(\mathrm{Cp}_{2} \mathrm{ZrCl}_{2} / \mathrm{MAO}\right)$ and a monomer solution are mixed continuously to initiate the polymerization. The polymerization occurs in a microtube reactor. The solution thus obtained is introduced to the second micromixer M2, where the polymerization is quenched by acetonitrile. The quenched solution is fed directly into the ESI source. The transient cationic species can be characterized by mass spectrometry. This is the first case where an alkyl zirconium cation intermediate in the homogeneous Ziegler-Natta polymerization of ethylene is detected directly. 


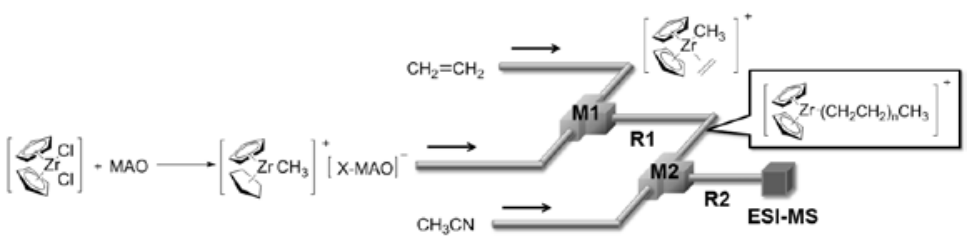

Figure 37 A flow microreactor system for Ziegler-Natta polymerization.

\subsection{Fabrication of Polymeric Structures inside Microchannels Using Fluid Flow}

\subsubsection{Polymerization on the Surface of Microchannels}

Surface-initiated polymerization is an attractive method for fabricating microfluidic devices [248-251]. For example, Beers et al reported surface-initiated atom transfer radical polymerization inside microchannels to produce flat gradient and patterned surfaces [252]. A solution of 2-hydroxyethyl methacrylate (HEMA) is introduced into the microchannel $(300 \mathrm{~mm} \times 8 \mathrm{~mm} \times 4.5 \mathrm{~cm})$, which was manufactured on a silicon wafer and functionalized with initiator-functionalized self-assembled monolayer (Figure 38). A polymer gradient is created inside the microchannel so that the thickness of the polymer brush decreases linearly from the inlet to the outlet.

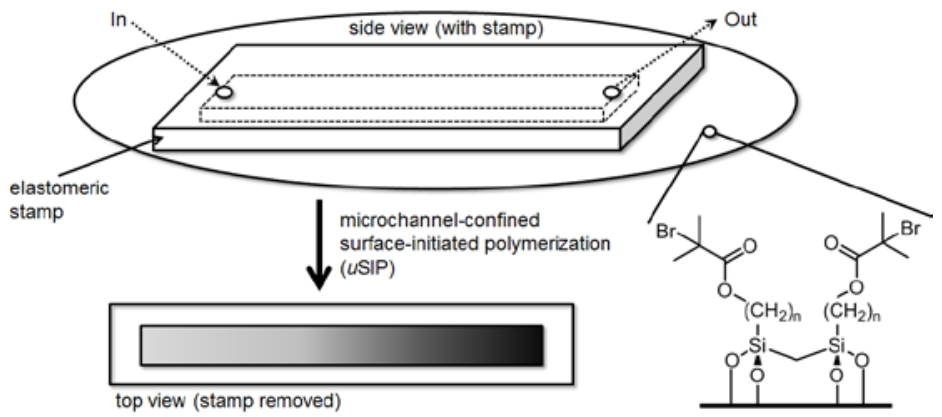

Figure 38 Microchannel confined surface-initiated polymerization ( $\mu$ SIP).

Microfluidic system can be applied to generate complex gradient solutions [253-255]. Recently, the generation of the solution gradient in a microfluidic passive mixer [256] is used to synthesize a surface-grafted statisticalcopolymer-brush composition gradient via surface-initiated atom transfer radical polymerization (Figure 39) [257]. Using surface-initiated polymerization, the monomer solution gadient of butyl methacrylate (nBMA) and 2-( $N, N-$ dimethylamino)ethyl methacrylate (DMAEMA) is applied to synthesize a statistical-copolymer-brush composition gradient. Burdick et al. also reported a similar approach to fabricating photo-cross-linked hydrogels with gradients of immobilized molecules and crosslinking densities using a microfluidics/photopolymerization process [258]. 


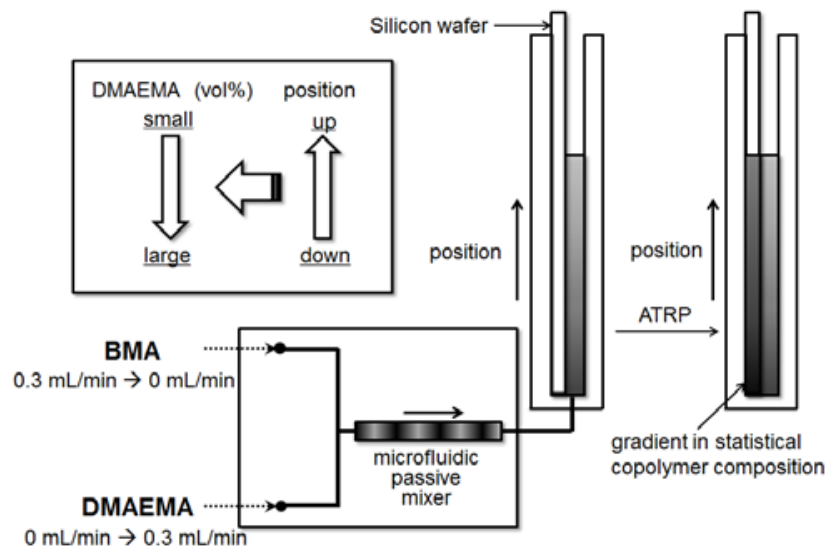

Figure 39 A schematic drawing of the setup used for the patterning of a surface with a statistical-copolymer-brush gradient.

\subsubsection{Fabrication of Polymer Membranes inside Microchannels}

Characteristic features of controlled laminar flow in microfluidics devices have been utilized in many applications such as diffusion-based separation and detection solvent extraction, mixing and hydrodynamic focusing [259, 260].

A method of microfabrication based on multicomponent laminar flow inside microchannels was developed by Whitesides and Kenis et al. [261, 262] Laminar streams of solutions enable a reaction at the interface between streams to make membranes inside the microchannel. For example, the reaction at the interface between two aqueous phases containing oppositely charged polymers (poly(sodium 4-styrenesulfonate) and hexadimethrine bromide) flowing laminarly in parallel produces a polymeric structure (membrane) deposited on glass at the laminar flow interface (Figure 40).

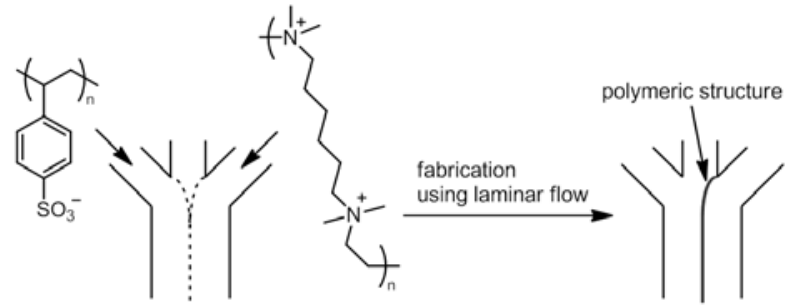

Figure 40 A polymeric structure deposited on glass at the laminar flow interface of two solutions of poly(sodium 4-styrenesulfonate) and hexadimethrine bromide.

Beer et al. demonstrated the formation of a laminar flow interface of immiscible liquids in a microchannel using partial chemical modification of the channel surface [263]. Synthesis of a polyamide nylon membrane by an interfacial 
polycondensation reaction of adipoyl chloride in 1,2-dichloroethane and hexamethylenediamine in water can be achieved in the cross-junction of the microchannel. Kitamori et al. also demonstrated design and synthesis of nylon polyamide membrane structures by an interfacial polycondensation reaction of adipoyl chloride in 1,2-dichloroethane and hexamethylenediamine in water (Figure 41) [264]. Uozumi et al. also reported that catalytic membrance-installed microchannel devices prepared from linear polymer ligands and palladium complexes and applied to Suzuki-Miyaura coupling reaction, oxidative cyclization of alkenols, allylic arylation, and hydrodehalogenation [265-269]. In addition, the influence of microfluidic device geometry and flow rate on the membrance formation by the interfacial polymerization was also demonstrated by Gargiuli et al [270].

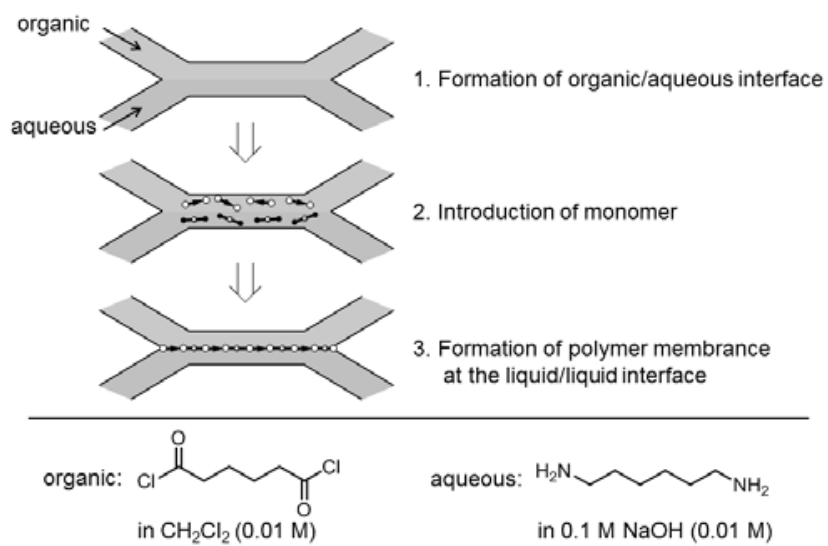

Figure 41 Polymer membrane formation under organic/aqueous two-phase flow in an X-shaped microchannel.

Single and parallel dual-membrane structures are successfully prepared by using multilayer flow such as organic/aqueous two layer flow and organic/aqueous/organic three-layer flow inside a microchannel, and this method can be applied to preparing surface modified polymer membranes (Figure 42). For example, horseradish peroxidase is immobilized on one side of the membrane surface, and this enzyme-modified membrane realizes substrate permeation and a subsequent reaction. 


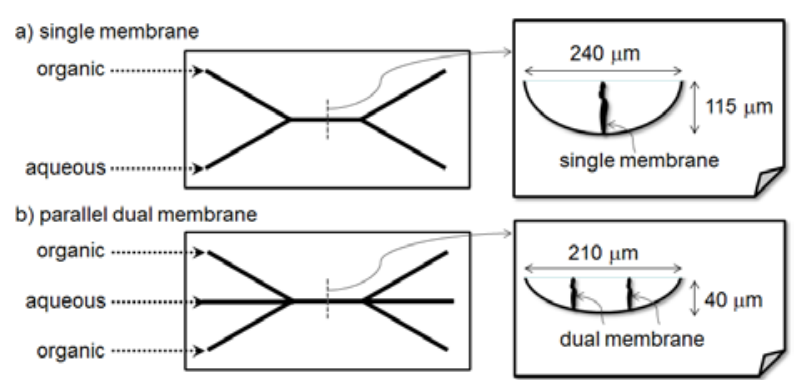

Figure 42 Channel patterns and cross-sectional views of the nylon membrane prepared inside a microchannel. (a) Single membrane formed under organic/aqueous two-layer flow, (b) parallel dual membranes formed under organic/aqueous/organic three-layer flow.

Protein-polymeric membrane in a microchannel is prepared by using a concentric laminar flow (Figure 43) [271]. Cross-linking condensation reaction of a cross-linked enzyme aggregate (CLEA) [272] with aldehyde groups, which react with amino groups of the enzyme in a concentric laminar flow results in the formation of the cylindrical enzyme-polymerized membrane on the inner wall of the microtube. The use of this technology for membrane formation in a microchannel can be extended to a broad range of functional proteins.

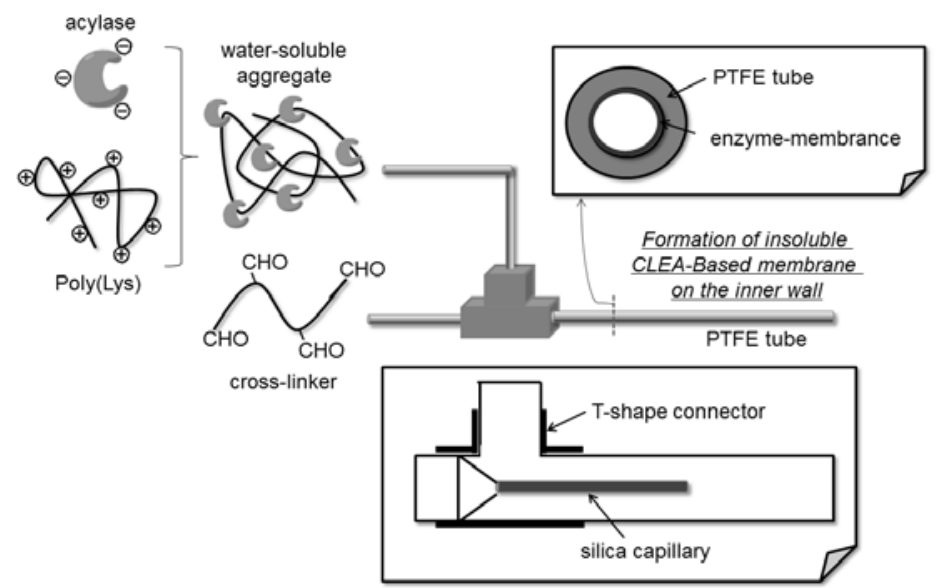

Figure 43 Schematic illustration of the procedure on preparation of enzymemembrane in micro-tube.

\subsection{Industrial Applications}

It is easily anticipated that flow microreactors can enjoy industrial applications by virtue of inherent advantages based on microstructures and flow nature. Significant progress in flow-microreactor-system-controlled polymerization to obtain structurally well-defined polymers has already been 
made to meet the demands of the chemical industry. No need of cryogenic conditions for anionic polymerization may enable commercial production. Some pilot plants have already been built and tested to examine the feasibility and durability of polymerization in flow microreactors. For example, a microchemical pilot plant for radical polymerization of MMA has been built by numbering up eight microtube reactors which can be operated continuously for 6 days to produce $4.0 \mathrm{~kg}$ of the polymer, indicating that flow microreactor systems can be used for industrial production of polymers (Figure 44) [171]. The information which has been accumulated in laboratories and pilot plants should profit the development of this field to realize commercial plants for making polymers in the future.

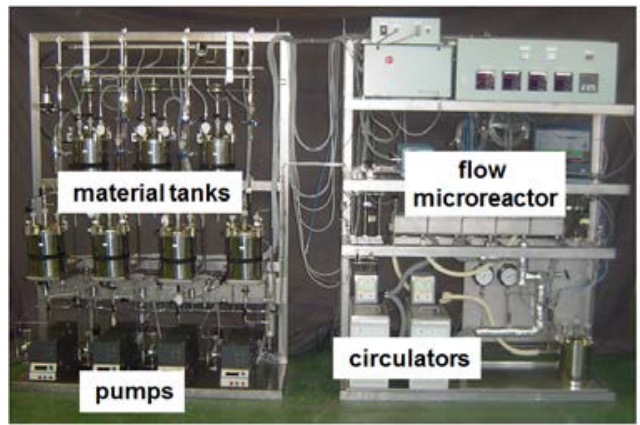

Figure 44 A pilot plant for radical polymerization.

\subsection{Conclusion}

The examples shown in this review article demonstrate that a variety of methods for polymer synthesis have been developed in flow microreactors. The continuous flow synthesis enables serial combinatorial synthesis, in which a variety of polymers in a sequential way using a single flow reactor with flow switch. Space integration, which enables the synthesis of structurally well-defined polymers without isolating living polymer ends, also enhances the power and speed of polymer synthesis. Because several test plants for continuous production have already been built, there is no doubt that flow microreactors can contribute to polymer production in industry.

In conclusion, continuous flow polymer synthesis will be an indispensable technology for research in a laboratory and production in industry. Various methods for polymer synthesis by virtue of characteristic features of flow microreactors will be developed, and they will work together to help meet the demanding expectations in polymer chemistry in the future.

\section{References}

[1] Hessel V, Hardt S, Löwe H (2004) Chemical micro process engineering. Wiley-VCH Verlag, Weinheim

[2] Wirth T (2008) Microreactors in organic synthesis and catalysis. Wiley-VCH Verlag, Weinheim 
[3] Hessel V, Renken A, Schouten JC et al (2009) Micro process engineering. Wiley-VCH Verlag, Weinheim

[4] Watts P, Wiles C (2011) Micro reaction technology in organic synthesis. CRC Press, New York

[5] Fletcher PDI, Haswell SJ, Pombo-Villar E et al (2002) Micro reactors: principles and applications in organic synthesis. Tetrahedron 58: 4735-4757

[6] Jähnisch K, Hessel V, Löwe $\mathrm{H}$ et al (2004) Chemistry in microstructured reactors. Angew. Chem., Int. Ed. 43: 406-446

[7] Kiwi-Minsker L, Renken A (2005) Microstructured reactors for catalytic reactions. Catalysis Today 110: 2-14

[8] Doku GN, Verboom W, Reinhoudt DN et al (2005) On-microchip multiphase chemistry - a review of microreactor design principles and reagent contacting modes. Tetrahedron 61: 2733-2742

[9] Watts P, Haswell SJ (2005) The application of micro reactors for organic synthesis. Chem. Soc. Rev. 34: 235-246

[10] Geyer K, Codee JDC, Seeberger PH (2006) Microreactors as tools for synthetic Chemists-the chemists' round-bottomed flask of the 21st century? Chem. Eur. J. 12: 8434-8442

[11] Whitesides G (2006) The origins and the future of microfluidics. Nature 442: 368-373

[12] deMello AJ (2006) Control and detection of chemical reactions in microfluidic systems. Nature 442: 394-402

[13] Song H, Chen DL, Ismagilov RF (2006) Reactions in droplets in microfluidic channels. Angew. Chem., Int. Ed. 45: 7336-7356

[14] Kobayashi J, Mori Y, Kobayashi S (2006) Multiphase organic synthesis in microchannel reactors. Chem. Asian J. 1: 22-35

[15] Brivio M, Verboom W, Reinhoudt DN (2006) Miniaturized continuous flow reaction vessels: influence on chemical reactions. Lab Chip 6: 329-344

[16] Mason BP, Price KE, Steinbacher JL et al (2007) Greener approaches to organic synthesis using microreactor technology. Chem. Rev. 107: 2300-2318

[17] Ahmed-Omer B, Brandtand JC, Wirth T (2007) Advanced organic synthesis using microreactor technology. Org. Biomol. Chem. 5: 733-740

[18] Watts P, Wiles C (2007) Recent advances in synthetic micro reaction technology. Chem. Commun. 443-467

[19] Fukuyama T, Rahman MT, Sato M et al (2008) Adventures in inner space: microflow systems for practical organic synthesis. Synlett 151-163

[20] Lin W, Wang Y, Wang S et al (2009) Integrated microfluidic reactors. Nano Today 4: 470-481

[21] McMullen JP, Jensen KF (2010) Integrated microreactors for reaction automation: new approaches to reaction development. Annu. Rev. Anal. Chem. 3: $19-42$

[22] Ley SV (2010) The changing face of organic synthesis. Tetrahedron 66: 6270-6292

[23] Webb D, Jamison TF (2010) Continuous flow multi-step organic synthesis. Chem. Sci. 1: 675-680 
[24] Yoshida J, Kim H, Nagaki A (2011) Green and sustainable chemical synthesis using flow microreactors. Chem. Sus. Chem. 4: 331-340

[25] Chambers RD, Holling D, Spink RCH et al (2001) Elemental fluorine Part 13. Gas-liquid thin film microreactors for selective direct fluorination. Lab Chip 1: $132-137$

[26] Jähnisch K, Baerns M, Hessel V et al (2000) Direct fluorination of toluene using elemental fluorine in gas/liquid microreactors. J. Fluorine Chem. 105: 117123

[27] Ducry L, Roberge DM (2005) Controlled autocatalytic nitration of phenol in a microreactor. Angew. Chem. Int. Ed. 44: 7972-7975

[28] Wakami H, Yoshida J (2005) Grignard exchange reaction using a microflow system: from bench to pilot plan. Org. Process Res. Dev. 9: 787-791

[29] Usutani H, Tomida Y, Nagaki A et al (2007) Generation and reactions of $o$ bromophenyllithium without benzyne formation using a microreactor. J. Am. Chem. Soc. 129: 3046-3047

[30] Nagaki A, Tomida Y, Usutani H et al (2007) Integrated micro flow synthesis based on sequential Br-Li exchange reactions of $p$-, $m$-, and $o$-dibromobenzenes. Chem. Asian J. 2: 1513-1523

[31] Nagaki A, Kim H, Yoshida J (2008) Aryllithium compounds bearing alkoxycarbonyl groups. Generation and reactions using a microflow system. Angew. Chem., Int. Ed. 47: 7833-7836

[32] Nagaki A, Takizawa E, Yoshida J (2009) Oxiranyl anion methodology using microflow systems. J. Am. Chem. Soc. 131: 1654-1655

[33] Nagaki A, Kim H, Yoshida J (2009) Nitro-substituted aryl lithium compounds in microreactor synthesis: Switch between kinetic and thermodynamic control. Angew. Chem., Int. Ed. 48: 8063-8065

[34] Tomida Y, Nagaki A, Yoshida J (2009) Carbolithiation of conjugated enynes with aryllithiums in microflow system and applications to synthesis of allenylsilanes. Org. Lett. 11: 3614-3617

[35] Nagaki A, Takizawa E, Yoshida J (2009) Generation and reactions of $\alpha$ silyloxiranyllithium in a microreactor. Chem. Lett. 38: 486-487

[36] Nagaki A, Takizawa E, Yoshida J (2009) Generations and reactions of $N$ - butylsulfonyl-aziridinyllithiums using microreactors. Chem. Lett. 38: 1060-1061

[37] Nagaki A, Kim H, Matsuo C et al (2010) Generation and reaction of cyanosubstituted aryllithium compounds using microreactors. Org. Biomol. Chem. 8: $1212-1217$

[38] Nagaki A, Kim H, Moriwaki Y et al (2010) A flow microreactor system enables organolithium reactions without protecting alkoxycarbonyl groups. Chem. Eur. J. 16: 11167-11177

[39] Nagaki A, Takizawa E, Yoshida J (2010) Generation and reactions of oxiranyllithiums by use of a flow microreactor system. Chem. Eur. J. 16: 1414914158

[40] Tomida Y, Nagaki A, Yoshida J (2011) Asymmetric carbolithiation of conjugated enynes: A flow microreactor enables the use of configurationally unstable intermediates before they epimerize. J. Am. Chem. Soc. 133: 3744-3747 
[41] Kim H, Nagaki A, Yoshida J (2011) A flow-microreactor approach to protecting-group-free synthesis using organolithium compounds. Nature Commun. 2: 264

[42] Nagaki A, Yamada S, Doi M et al (2011) Flow microreactor synthesis of disubstituted pyridines from dibromopyridines via $\mathrm{Br} / \mathrm{Li}$ exchange without using cryogenic conditions. Green Chem. 13: 1110-1113

[43] Nagaki A, Tokuoka S, Yamada S et al (2011) Perfluoroalkylation in flow microreactors: Generation of perfluoroalkyllithiums in the presence and absence of electrophiles. Org. Biomol. Chem. 9: 7559-7563

[44] Asai T, Takata A, Nagaki A et al (2012) Practical synthesis of photochromic diarylethenes in integrated flow microreactor. ChemSusChem 5: 339-350

[45] Nagaki A, Matsuo C, Kim S et al (2012) Lithiation of 1,2-dichloroethene in flow microreactors: Versatile synthesis of alkenes and alkynes by precise residence-time control. Angew. Chem. Int. Ed. 51: 3245-3248

[46] He P, Watts P, Marken F et al (2006) Self-supported and clean one-step cathodic coupling of ... Derivatives in a micro flow reactor. Angew. Chem., Int. Ed. 45: 4146-4149

[47] Tanaka K, Motomatsu S, Koyama K et al (2007) Large-scale synthesis of immunoactivating natural product, pristane, by continuous microfluidic dehydration as the key step. Org. Lett. 9: 299-302

[48] Sahoo HR, Kralj JG, Jensen KF (2007) Multi-step continuous flow microchemical synthesis involving multiple reactions and separations. Angew. Chem., Int. Ed. 46: 5704-5708

[49] Hornung CH, Mackley MR, Baxendale IR et al (2007) A microcapillary flow disc reactor for organic synthesis. Org. Process Res. Dev. 11: 399-405

[50] Fukuyama T, Kobayashi M, Rahman MT et al (2008) Spurring radical reactions of organic halides with tin hydride and TTMSS using microreactors. Org. Lett. 10: 533-536

[51] Tricotet T, O’Shea DF (2010) Automated generation and reactions of 3hydroxymethylindoles in continuous-flow microreactors. Chem. Eur. J. 16: 66786686

[52] Browne DL, Baumann M, Harji BH et al (2011) A new enabling technology for convenient laboratory scale continuous flow processing at low temperatures. Org. Lett. 13: 3312-3315

[53] Carter CF, Lange H, Sakai D et al (2011) Diastereoselective chain elongation reactions using microreactors for application in complex molecule assembly. Chem. Eur. J. 17: 3398-3405

[54] Zaborenko N, Bedore MW, Jamison TF et al (2011) Kinetic and scale-up investigations of epoxide aminolysis in microreactors at high temperatures and pressures. Org. Process Res. Dev. 15: 131-139

[55] Noél T, Kuhn S, Musachio AJ et al (2011) Suzuki-Miyaura cross-coupling reactions in flow: multistep synthesis enabled by a microfluidic extraction. Angew. Chem. Int. Ed. 50: 5943-5946

[56] Gutierrez AC, Jamison TF (2011) Continuous photochemical generation of catalytically active $[\mathrm{CpRu}]^{+}$complexes from $\mathrm{CpRu}\left(\eta^{6}-\mathrm{C}_{6} \mathrm{H}_{6}\right) \mathrm{PF}_{6}$ Org. Lett. 13: 6414-6417 
[57] Hessel V, Serra C, Löwe H et al (2005) Polymerisationen in mikrostrukturierten reaktoren: ein überblick. Chem. Ing. Tech. 77: 1693-1714 [58] Steinbacher JL, Mcquade DT (2006) Polymer chemistry in flow: New polymers, beads, capsules, and fibers. Journal of Polymer Science: Part A: Polymer Chemistry 44: 6505-6533

[59] Wilms D, Klos J, Frey H (2008) Microstructured reactors for polymer synthesis: A renaissance of continuous flow processes for tailor-made macromolecules? Macromol. Chem. Phys. 209: 343-356

[60] Bally F, Serra CA, Hessel V et al (2010) Homogeneous polymerization: Benefits brought by microprocess technologies to the synthesis and production of polymers. Macromol. React. Eng. 4: 543-561

[61] Bally F, Serra CA, Hessel V et al (2011) Micromixer-assisted polymerization processes. Chem. Eng. Sci. 66: 1449-1462

[62] Serra CA, Chang Z (2008) Microfluidic-assisted synthesis of polymer particles. Chem. Eng. Technol. 31: 1099-1115

[63] Kakuta M, Bessoth FG, Manz A (2001) Microfabricated devices for fluid mixing and their application for chemical synthesis. Chem. Rec. 1: 395-405

[64] Hessel V, Löwe H, Schönfeld F (2005) Micromixers - a review on passive and active mixing principles. Chem. Eng. Sci. 60: 2479-2501

[65] Ehrfeld W, Golbig K, Hessel V et al (1999) Characterization of mixing in micromixers by a test reaction: single mixing unites and mixer arrays. Ind. Eng. Chem. Res. 38: 1075-1082

[66] Lu H, Schmidt MA, Jensen KF (2001) Photochemical reactions and on-line UV detection in microfabricated reactors. Lab Chip 1: 22-28

[67] Ueno K, Kitagawa F, Kitamura N (2002) Photocyanation of pyrene across an Oil/ water interface in a polymer microchannel. Lab Chip 2: 231-234

[68] Fukuyama T, Hino Y, Kamata N et al (2004) Quick execution of [2+2] type photochemical cycloaddition reaction by continuous flow system using a glassmade microreactor. Chem. Lett. 33: 1430-1431

[69] Maeda H, Mukae, H, Mizuno K (2005) Enhanced efficiency and regioselectivity of intramolecular $(2 \pi+2 \pi)$ photocycloaddition of 1cyanonaphthalene derivative using microreactors. Chem. Lett. 34: 66-67

[70] Jähnisch K, Dingerdissen U (2005) For an example of endoperoxide quenching in a continuous flow system. Chem. Eng. Technol. 28: 426-427

[71] Hook BD, Dohle W, Hirst PR et al (2005) A practical flow reactor for continuous organic photochemistry. J. Org. Chem. 70: 7558-7564

[72] Matsushita Y, Kumada S, Wakabayashi K et al (2006) Photocatalytic reduction in microreactors. Chem. Lett. 35: 410-411

[73] Sugimoto A, Sumino Y, Takagi M et al (2006) High throughput evaluation of the production of substituted acetylenes by the Sonogashira reaction followed by the Mizoroki-Heck reaction in ionic liquids, in situ, using a novel array reactor. Tetrahedron Lett. 47: 6197-6200

[74] Matsushita Y, Ohba N, Suzuki T et al (2008) Photocatalytic reduction of $\mathrm{CO}_{2}$ in a photocatalytic microreactor under gas- liquid-solid multiphase-flow condition ex- cited by 365-nm UV-LEDs. Catalysis Today, 132: 153-158 
[75] Horie T, Sumino M, Tanaka T et al (2010) Photodimerization of maleic anhydride in a microreactor without clogging. Org. Process Res. Dev. 14: 405-410 [76] Yoshida J, Kataoka K, Horcajada R et al (2008) Modern strategies in electroorganic synthesis. Chem. Rev. 108: 2265-2299

[77] Yoshida J (2009) Organic electrochemistry, microreactors, and their synergy. Interface Summer: 40-45

[78] Löwe H, Ehrfeld W (1999) State-of-the-art in microreaction technology: concepts, man-. ufacturing and applications. Electrochim. Acta 44: 3679-3689

[79] Suga S, Okajima M, Fujiwara K et al (2001) "Cation flow" method. A new approach to conventional and combinatorial organic syntheses using electrochemical microflow systems. J. Am. Chem. Soc. 123: 7941-7942

[80] Kupper M, Hessel V, Löwe H et al (2003) Micro reactor for electroorganic synthesis in the simulated moving bed-reaction and separation environment. Electrochim. Acta 48: 2889-2896

[81] Paddon CA, Pritchard GJ, Thiemann T et al (2002) Paired electrosynthesis: micro-flow cell processes with and without added electrolyte. Electrochem. Commun. 825-831

[82] Horii D, Atobe M, Fuchigami T et al (2005) Self-supported paired electrosynthesis of 2,5-dimethoxy-2,5-dihydrofuran using a thin layer flow cell without intentionally added supporting electrolyte. Electrochem. Commun. 7: 3539

[83] Horcajada R, Okajima M, Suga S et al (2005) Microflow electroorganic synthesis without supporting electrolyte. Chem. Commun. 1303-1305

[84] Suga S, Okajima M, Fujiwara K et al (2005) Electrochemical combinatorial organic syntheses using micro flow systems. QSAR Comb. Sci. 24: 728-741

[85] Horii D, Atobe M, Fuchigami T et al (2006) Self-supported methoxylation and acetoxylation electrosynthesis using a simple thin-layer flow cell. J. Electrochem. Soc. 153: D143-D147

[86] Horii D, Fuchigami T, Atobe M (2007) A new approach to anodic substitution reaction using parallel laminar flow in a micro-flow reactor. J. Am. Chem. Soc. 129: 11692-11693

[87] Yoshida J (2008) Flash chemistry. Fast organic synthesis in microsystems. Wiley-Blackwell

[88] Yoshida J (2010) Flash chemistry: flow microreactor synthesis based on high-resolution reaction time control. Chem. Record, 10: 332-341

[89] Yoshida J, Nagaki A, Yamada T (2008) Flash chemistry: fast chemical synthesis by using microreactors. Chem. Eur. J. 14: 7450-7459

[90] Yoshida J (2005) Flash chemistry using electrochemical method and microsystems. Chem. Commun. 4509-4516

[91] Higashimura T (1971) Cationic polymerization. Kagaku Dojin, Kyoto

[92] Matyjaszewski K, Sawamoto M (1996) In: Matyjaszewski K (ed) Cationic polymerizations. Marcel Dekker, New York

[93] Prakash GKS, Schleyer PVR (1997) Stable carbocation chemistry. Wiley Interscience, New York

[94] Olah GA (1995) My search for carbocations and their role in chemistry (nobel lecture). Angew. Chem. Int. Ed. 34: 1393-1405 
[95] Olah GA (2001) 100 years of carbocations and their significance in chemistry. J. Org. Chem. 66: 5943-5957

[96] Miyamoto M, Sawamoto M, Higashimura T (1984) Living polymerization of isobutyl vinyl ether with the hydrogen iodide/iodine initiating system. Macromolecules 17: 275-268

[97] Aoshima S, Higashimura T (1989) Living cationic polymerization of vinyl monomers by organoaluminum halides. Living polymerization of isobutyl vinyl ether by EtA1C1 12 in the presence of ester additives. Macromolecules 22: 10091013

[98] Kishimoto Y, Aoshima S, Higashimura T (1989) Living cationic polymerization of vinyl monomers by organoaluminum halides. Polymerization of isobutyl vinyl ether by $\mathrm{EtA} 1 \mathrm{C} 1_{2}$ in the presence of ether additives. Macromolecules 22: 3877-3882

[99] Puskas JE, Kaszas J (2000) Living carbocationic polymerization of resonance-stabilized monomers. Prog. Polym. Sci. 25: 403-452

[100] Inagaki N, Ando T, Sawamoto M et al (2004) Living cationic plymerization with micromixer: syntheses of end-functinalized polymers and multiblock copolymer. Polymer Reprints, Japan 53: 2416-2417

[101] Rys P (1976) Disguised chemical selectivities. Acc. Chem. Res. 10: 345-351 [102] Yoshida J, Nagaki A, Iwasaki T et al (2005) Enhancement of chemical selectivity by microreactors. Chem. Eng. Tech. 3: 259-266

[103] Nagaki A, Togai M, Suga S et al (2005) Control of extremely fast competitve consecutive reactions using micromixing. J. Am. Chem. Soc. 127: 11666-11675

[104] Suga S, Nagaki A, Yoshida J (2003) Highly selective Friedel-Crafts monoalkylation using micromixing. Chem. Commun. 354-355

[105] Suga S, Nagaki A, Tsutsui Y et al (2003) “ $N$-Acyliminium ion pool” as hetero diene in [4+2] cycloaddition reaction. Org. Lett. 5: 945-949

[106] Suga S, Tsutsui Y, Nagaki A et al (2005) Cycloaddition of " $N$-acyliminium ion pool” with carbon-carbon multiple bond. Bull. Chem.Soc. Jpn. 78: 1206-1217

[107] Nagaki A, Takabayashi N, Tomida Y et al (2008) Synthesis of unsymmetrical biaryls by means of mono-selective reaction of polyhaloarenes using integrated microflow system. Org. Lett. 18: 3937-3940

[108] Nagaki A, Takabayashi N, Tomida Y et al (2009) Synthesis of unsymmetrically substituted biaryls via sequential lithiation of dibromobiaryls using integrated microflow systems. Beilstein J. Org. Chem. 5: No16

[109] Ishigaki Y, Suzuki T, Nishida J et al (2011) Hysteretic tricolor electrochromic systems based on the dynamic redox properties of unsymmetrically substituted dihydrophenanthrenes and biphenyl-2,2'-diyl dications: Efficient precursor synthesis by a flow microreactor method. Materials 4: 1906-1926

[110] Suzuki T, Uchimura Y, Ishigaki Y et al (2012) Non-additive substituent effects on expanding prestrained $\mathrm{C}-\mathrm{C}$ bond in crystal: X-ray analyses on unsymmetrically substituted tetraarylpyracenes prepared by a flow microreactor method. Chem. Lett. 41: 541-543 
[111] Midorikawa K, Suga S, Yoshida J (2006) Selective monoiodination of aromatic compounds with electrochemically generated $\mathrm{I}^{+}$using micromixing. Chem. Comun. 3794-3796

[112] Kataoka K, Hagiwara Y, Midorikawa K et al (2008) Practical electrochemical iodination of aromatic compounds. Org. Process Res. Dev. 12: 1130-1136

[113] Hessel V, Hofmann C, Löwe H et al (2004) Selectivity gains and energy savings for the industrial phenyl boronic acid process using micromixer/tubular reactors. Org. Process Res. Dev. 8: 511-523

[114] Yoshida J, Suga S, Suzuki S et al (1999) Direct oxidative carbon-carbon bond formation using the "cation pool" method. Generation of iminium cation pools and their reaction with carbon nucleophiles. J. Am. Chem. Soc. 121: 95469549

[115] Yoshida J, Suga S (2002) Basic concepts of “cation pool” and "cation flow” methods and their applications in conventional and combinatorial organic synthesis. Chem. Eur. J. 8: 2650-2658

[116] Suga S, Nishida T, Yamada D et al (2004) Three-component coupling based on the "cation pool" method. J. Am. Chem. Soc. 126: 14338-14339

[117] Suga S, Suzuki S, Yamamoto A et al (2000) Electrooxidative generation and accumulation of alkoxycarbenium ions and their reactions with carbon nucleophiles. J. Am. Chem. Soc. 122: 10244-10245

[118] Suga S, Matsumoto K, Ueoka K et al (2006) Indirect cation pool method. Rapid generation of alkoxycarbenium ion pools from thioacetals. J. Am. Chem. Soc. 128: 7710-7711

[119] Suzuki S, Matsumoto K, Kawamura K et al (2004) Generation of alkoxycarbenium ion pools from thioacetals and applications to glycosylation chemistry. Org. Lett. 6: 3755-3758

[120] Okajima M, Suga S, Itami K et al (2005) “Cation pool” method based on C$\mathrm{C}$ bond dissociation. Effective generation of monocations and dications. J. Am. Chem. Soc. 127: 6930-6931

[121] Suga S, Matsumoto K, Ueoka K et al (2006) Indirect cation pool method. Rapid generation of alkoxycarbenium ion pools from thioacetals. J. Am. Chem. Soc. 128: 7710-7711

[122] Saito K, Ueoka K, Matsumoto K et al (2011) Indirect cation flow method. Flash generation of alkoxycarbenium ions and studies on stability of glycosyl cations. Angew. Chem., Int. Ed. 50: 5153-5156

[123] Okajima M, Soga K, Nokami T et al (2006) Oxidative generation of diarylcarbenium ion pools. Org. Lett. 8: 5005-5007

[124] Okajima M, Soga K, Watanabe $T$ et al (2009) Generation of diarylcarbenium ion pools via electrochemical C-H bond dissociation. Bull. Chem. Soc. Jpn. 82: 594-599

[125] Nokami T, Shibuya A, Tsuyama H et al (2007) Electrochemical generarion of glycosyl triflate pools. J. Am. Chem. Soc. 129: 10922-10928

[126] Nagaki A, Kawamura K, Suga S et al (2004) "Cation pool” initiated controlled/living polymerization using microsystems. J. Am. Chem. Soc. 126: 14702-14703 
[127] Because the yield of $N$-acyliminium ion from precursor is estimated as ca. $80 \%$ based on the reactions with various nucleophiles, 1.2 equiv of precursor is used when 1.0 equiv of $N$-acyliminium ion is needed for polymerization.

[128] Ehrfeld W, Golbig K, Hessel V et al (1999) Characterization of mixing in micromixers by a test reaction: single mixing units and mixer arrays. Ind. Eng. Chem. Res. 38: 1075-1082

[129] Kishimoto Y, Aoshima S, Higashimura T (1989) Living cationic polymerization of vinyl monomers by organoaluminum halides. Polymerization of isobutyl vinyl ether by $\mathrm{EtA} 1 \mathrm{C} 1_{2}$ in the presence of ether additives. Macromolecules 22: 3877-3882

[130] Cho CG, Feit BA, Webster OW (1990) Cationic polymerization of isobutyl vinyl ether: livingness enhancement by dialkyl sulfide. Macromolecules 23: 19181923

[131] Iwasaki T, Nagaki A, Yoshida J (2007) Microsystem controlled cationic polymerization of vinyl ethers initiated by $\mathrm{CF}_{3} \mathrm{SO}_{3} \mathrm{H}$. Chem. Commun. 1263-1265 [132] Nagaki A, Iwasaki T, Kawamura K et al (2008) Microflow system controlled carbocationic polymerization of vinyl ethers. Chem. Asian J. 3: 15581567

[133] Dittmer T, Gruber F, Nuyken O (1989) Cationic polymerization of bis(1alkylvinyl)benzenes and related monomers - Structure elucidation of 1,1,3trimetnyl substituted polyindane. Makromol. Chem. 190: 1755-1770

[134] Dittmer T, Gruber F, Nuyken O (1989) Cationic polymerization of bis(1alkylvinyl)benzenes and related monomers - Controlled syntheses of 1,1,3trimetnyl substitued polyindanes. Makromol. Chem. 190: 1771-1790

[135] Iwasaki T, Yoshida J (2007) $\mathrm{CF}_{3} \mathrm{SO}_{3} \mathrm{H}$ initiated cationic polymerization of diisopropenylbenzenes in macrobatch and microflow systems. Macromol. Rapid Commun. 28: 1219-1224

[136] Szwarc M (1956) Living polymers. Nature 178: 1168-1169

[137] Hsieh HL, Quirk RP (1996) Anionic polymerization: principles and practical applications; Marcel Dekker: New York,

[138] Jagur-grodzinski J (2002) Functional polymers by living anionic polymerization. J. Polym. Sci., Part A: Polym. Chem. 40: 2116-2133

[139] Hong K, Uhrig D, Mays JW (1999) Current opinion in solid state and material science 531

[140] Hirao A, Loykulnant S, Ishizone T (2002) Recent advance in living anionic polymerization of functionalized styrene derivatives. Prog. Polym. Sci. 27: 13991471

[141] Hadjichristidis N, Pitsikalis M, Pispas S et al (2001) Polymers with complex architecture by living anionic polymerization. Chem. Rev. 101: 3747-3792

[142] Frechet JMJ (1994) Functional polymers and dendrimers: reactivity, molecular architecture, and interfacial energy. Science $263: 1710-1715$

[143] Percec V (2001) Frontiers in polymer chemistry. Chem. Rev. 101: issue 12 [144] Jagur-Grodzinski J (2006) Living and controlled polymerization: synthesis, characterization, and properties of the respective polymers and copolymers; NOVA: New York

[145] Bhattacharyya DN, Lee CL, Smid J et al (1965) J. Phys. Chem. 69: 612 
[146] Figini RV, Hostalka H, Hurm K et al Phys. Chem. 45: 269

[147] Baskaran D, Müller AHE (1997) Kinetic investigation on metal free anionic polymerization of methyl methacrylate using tetraphenylphosphonium as the counterion in tetrahydrofuran. Macromolecules 30: 1869-1874

[148] Hofe T, Maurer A, Müller AHE (1998) GIT Labor Fachz. 42: 1127

[149] Tonhauser C, Frey H (2010) A road less traveled to functional polymers: Epoxide termination in living carbanionic polymer synthesis. Macromol. Rapid Commun. 31: 1938-1947

[150] Nagaki A, Tomida Y, Yoshida J (2008) Microflow system controlled anionic polymerization of styrenes. Macromolecules 41: 6322-6330

[151] Wurm F, Wilms D, Klos J et al (2008) Carbanions on trap - Living anionic polymerization in a microstructured reactor. Macromol. Chem. Phys. 209: 11061114

[152] Yoshida J, Saito K, Nokami T. et al (2011) Space integration of reactions: An approach to increase capability of organic synthesis. Synlett 9: 1189-1194

[153] Suga S, Yamada D, Yoshida J (2010) Cationic three-component coupling invollving an optically active enamine derivative. From time integration to space integration of reactions. Chem. Lett. 39: 404-405

[154] Nagaki A, Kenmoku A, Moriwaki Y et al Cross-coupling in a flow microreactor. Space integration of lithiation and Murahashi coupling. Angew. Chem., Int. Ed. 49: 7543-7547

[155] Nagaki A, Uesugi Y, Tomida Y et al Homocoupling of aryl halides in flow: Space integration of lithiation and $\mathrm{FeCl}_{3}$ promoted homocoupling. Beilstein $\mathrm{J}$. Org. Chem. 7: 1064-1069

[156] Nagaki A, Imai K, Kim H et al (2011) Flash synthesis of TAC-101 and its analogues from 1,3,5-tribromobenzene using Integrated flow microreactor systems. RSC Adv. 1: 758-760

[157] Nagaki A, Moriwaki Y, Haraki S et al (2012) Cross-coupling of aryllithiums with aryl and vinyl halides in flow microreactors. Chem. Asian J. 7: 1061-1068

[158] Tonhauser C, Wilms D, Wurm F et al (2010) Multihydroxyl-functional polystyrenes in continuous flow. Macromolecules 43: 5582-5588

[159] Pennisi RW, Fetters LJ (1988) Preparation of asymmetric three-arm polybutadiene and polystyrene stars. Macromolecules 21: 1094-1099

[160] Iatrou H, Hadjichristidis N (1992) Synthesis of a model 3-miktoarm star terpolymer. Macromolecules 25: 4649-4651

[161] Rózga-Wijas K, Chojnowski J, Fortuniak W et al (2003) Branched functionalised polysiloxane-silica hybrids for immobilisation of catalysts. J. Mater. Chem. 13: 2301-2310

[162] Iida K, Chastek TQ, Beers KL et al (2009) Living anionic polymerization using a microfluidic reactor. Lab Chip 9: 339-345

[163] Zune C, Jérôme R (1999) Anionic polymerization of methacrylic monomers: characterization of the propagating species. Prog. Polym. Sci. 24: 631664

[164] Baskaran D (2003) Strategic developments in living anionic polymerization of alkyl (meth)acrylates. Prog. Polym. Sci. 28: 521-581 
[165] Nagaki A, Tomida Y, Miyazaki A et al (2009) Microflow system controlled anionic polymerization of MMA. Macromolecules 42: 4384-4387

[166] Nagaki A, Miyazaki A, Tomida Y et al (2011) Anionic polymerization of alkyl methacrylates using flow microreactor systems. Chem. Eng. J. 167: 548-555 [167] Nagaki A, Miyazaki A, Yoshida J (2010) Synthesis of polystyrenespoly(alkyl methacrylates) block copolymers via anionic polymerization using an integrated flow microreactor system. Macromolecules 43: 8424-8429

[168] Matyjaszewski K, Davis TP (2002) Handbook of radical polymerization; Wiley: New York

[169] Iwasaki T, Yoshida J (2005) Free radical polymerization in microreactors. Significant improvement in molecular weight distribution control. Macromolecules 38: 1159-1163

[170] Leveson P, Dunk WAE, Jachuck RJ (2004) Investigation of shear effects on styrene free radical polymerization using a narrow channel reactor. J. Appl. Polym. Sci. 94: 1365-1369

[171] Iwasaki T, Kawano N, Yoshida J (2006) Radical polymerization using micro flow system. Numbering-up of microreactoes and continuous operation. Org. Process Res. Dev. 10: 1126-1131

[172] Bayer T, Pysall D, Wachsen O (2000) Micro mixing effects in continuous radical polymerization. $3^{\text {rd }}$ International Conference on Microreaction Technology $165-170$

[173] GmbH A, Pysall D, Wachsen O et al (1999) Method and device for continuous production of polymers. Patent WO/1999/054362

[174] Serra C, Sary N, Schlatter G et al (2005) Numerical simulation of polymerization in interdigital multilamination micromixers. Lab Chip 5: 966-973

[175] Serra C, Schlatter G, Sary N et al (2007) Free radical polymerization in multilaminated microreactors: 2D and 3D multiphysics CFD modelling. Microfluid. Nanofluid. 3: 451-461

[176] Rollin AL, Patterson I, Huneault R et al (1977) The effect of flow regime on the continuous emulsion polymerization of styrene in a tubular reactor. Can. J. Chem. Eng. 55: 565-571

[177] Dalpe J, Bataille P (1989) Loop polymerization of vinyl acetate. J. Appl. Polym. Sci. 38: 2237-2244

[178] Abad C, de la Cal JC, Asua JM (1995) Start-up procedures in the emulsion copolymerization of vinyl esters in a continuous loop reactor. Polymer 36: 42934299

[179] Ouzine K, Graillat C, McKenna T (2004) Continuous tubular reactors for latex production: Conventional emulsion and miniemulsion polymerizations. J. Appl. Polym. Sci. 91: 2195-2207

[180] Matyjaszewski K, Davis TP (2002) Handbook of radical polymerization; Wiley-Interscience: New York

[181] Moad G, Solomon DH (2006) The chemistry of radical polymerization; Elsevier: Amsterdam

[182] Braunecke WA, Matyjaszewski K (2007) Controlled/living radical polymerization: Features, developments, and perspectives. Prog. Polym. Sci. 32: 93-146 
[183] Matyjaszewski K (1998) “Controlled radical polymerization”, Am. Chem. Soc., Washington, DC Vol. 685

[184] Matyjaszewski K (2000) "Controlled/living radical polymerization: Progress in ATRP, NMP, and RAFT”, Am. Chem. Soc., Washington, DC Vol. 768

[185] Otsu T (2000) Iniferter concept and living radical polymerization. J. Polym. Sci. Pol. Chem. 38: 2121-2136

[186] Matyjaszewski K, Xia J (2001) Atom transfer radical polymerization. Chem. Rev. 101: 2921-2990

[187] Ouchi M, Terashima T, Sawamoto M (2008) Precision control of radical polymerization via transition metal catalysis: From dormant species to designed catalysts for precision functional polymers. Acc. Chem. Res. 41: 1120-1132

[188] Kamigaito M, Ando T, Sawamoto M (2001) Metal-catalyzed living radical polymerization. Chem. Rev. 101: 3689-3746

[189] Wang J, Matyjaszewski K (1995) Controlled/"living" radical polymerization. halogen atom transfer radical polymerization promoted by a $\mathrm{Cu}(\mathrm{I}) / \mathrm{Cu}(\mathrm{II})$ redox process. Macromolecules 28: 7901-7910

[190] Wang J, Matyjaszewski K (1995) Atom transfer radical polymerization in the presence of transition metal complexes. J. Am. Chem. Soc. 117: 5614-5615

[191] Kato M, Kamigaito M, Sawamoto M et al (1995) Polymerization of methyl methacrylate with the carbon tetrachloride/dichlorotris(triphenylphosphine)ruthenium(II)/methylaluminum bis(2,6-di-tertbutylphenoxide) initiating system: Possibility of living radical polymerization. Macromolecules 28: 1721-1723

[192] Moad G, Rizzardo E, Thang SH (2008) Radical addition-fragmentation chemistry in polymer synthesis. Polymer 49: 1079-1131

[193] Löwe AB, McCormick CL (2007) Reversible addition-fragmentation chain transfer (RAFT) radical polymerization and the synthesis of water-soluble (co)polymers under homogeneous conditions in organic and aqueous media. Prog. Polym. Sci. 32: 283-351

[194] Chiefari J, Chong YKB, Ercole F et al (1998) Living free-radical polymerization by reversible addition-fragmentation. Chain transfer: The RAFT process. Macromolecules 31: 5559-5562

[195] Hawker CJ, Bosman AW, Harth E (2001) New polymer synthesis by nitroxide mediated living radical polymerizations. Chem. Rev. 101: 3661-3688

[196] Studer A (2004) Tin-free radical chemistry using the persistent radical effect: alkoxyamine isomerization, addition reactions and polymerizations. Chem. Soc. Rev. 33: 267-263

[197] Grubbs RB (2011) Nitroxide-mediated radical polymerization: Limitations and versatility. Polym. Rev. 51: 104-137

[198] David G, Boyer C, Tonnar J, Ameduri B et al (2006) Use of iodocompounds in radical polymerization. Chem. Rev. 106: 3936-3962

[199] Poli R (2006) Relationship between one-electron transition-metal reactivity and radical polymerization processes. Angew. Chem. Int. Ed. 45: 5058-5070 
[200] Yamago S (2009) Precision polymer synthesis by degenerative transfer controlled/living radical polymerization using organotellurium, organostibine, and organobismuthine chain transfer agents. Chem. Rev. 109: 5051-5068

[201] Yamago S (2006) The development of organotelluriu-mediated and organostibine-mediated living radical polymerization reactions. J. Polym. Sci., Part A: Polym. Chem. 44: 1-12

[202] Goto A, Kwak Y, Fukuda T et al (2003) Mechanism-based invention of high-speed living radical polymerization using organotellurium compounds and azo-initiators. J. Am. Chem. Soc. 125: 8720-8721

[203] Yamago S, Iida K, Yoshida J (2002) Organotellurium compounds as novel initiators for controlled/living radical polymerizations. Synthesis of functionalized polystyrenes and end-group modifications. J. Am. Chem. Soc. 124: 2874-2875

[204] Kwak Y, Goto A, Fukuda T et al (2006) A systematic study on activation processes in organotellurium-mediated living radical polymerizations (TERPs) of styrene, methyl methacrylate, methyl acrylate, and vinyl acetate. Macromolecules 39: 4671-4679

[205] Yamago S, Iida K, Yoshida J (2002) Synthesis of poly(meth)acrylate derivatives and their di- and triblock copolymers. J. Am. Chem. Soc. 124: 1366613667

[206] Matyjaszewski K (1997) Controlled radical polymerization, American Chemical Society, Washington, DC ACS Symp. Ser., Vol. 685

[207] Shen Y, Zhu S, Pelton R (2000) Packed column reactor for continuous atom transfer radical polymerization: Methyl methacrylate polymerization using silica gel supported catalyst. Macromol. Rapid Commun. 21: 956-959

[208] Shen Y, Zhu S (2002) Continuous atom transfer radical block copolymerization of methacrylates. AIChE Journal 48: 2609-2619

[209] Wu T, Mei Y, Cabral JT et al (2004) A new synthetic method for controlled polymerization using a microfluidic system. J. Am. Chem. Soc. 126: 9880-9881

[210] Save M, Weaver JVM, Armes SP et al (2002) Atom transfer radical polymerization of hydroxy-functional methacrylates at ambient temperature: comparison of glycerol monomethacrylate with 2-hydroxypropyl methacrylate. Macromolecules 35: 1152-1159

[211] Wu T, Mei Y, Xu C et al (2005) Block copolymer PEO-b-PHPMA synthesis using controlled radical polymerization on a chip. Macromol. Rapid Commun. 26: 1037-1042

[212] Russum JP, Jones CW, Schork FJ (2004) Continuous reversible additionfragmentation chain transfer polymerization in miniemulsion utilizing a multi-tube reaction system. Macromol. Rapid Commun. 25: 1064-1068

[213] Russum JP, Jones CW, Schork FJ (2005) Continuous living polymerization in miniemulsion using reversible addition fragmentation chain transfer (RAFT) in a tubular reactor. Ind. Eng. Chem. Res. 44: 2484-2493

[214] Diehl C, Laurino P, Azzouz N et al (2010) Accelerated continuous flow RAFT polymerization. Macromolecules 43: 10311-10314

[215] Hornung CH, Guerrero-Sanchez C, Brasholz M et al (2011) Controlled RAFT polymerization in a continuous flow microreactor. Org. Process Res. Dev. 15: 593-601 
[216] Rosenfeld C, Serra C, Brochon C et al (2007) High-temperature nitroxidemediated radical polymerization in a continuous microtube reactor: Towards a better control of the polymerization reaction. Chem. Eng. Sci. 62: 5245-5250

[217] Enright TE, Cunningham MF, Keoshkerian B (2005) Nitroxide-mediated polymerization of styrene in a continuous tubular reactor. Macromol. Rapid Commun. 26: 221-225

[218] Enright TE, Cunningham MF, Keoshkerian B (2010) Nitroxide-mediated bulk and miniemulsion polymerization in a continuous tubular reactor: Synthesis of homo-, di- and triblock copolymers. Macromol. React. Eng. 4: 186-196

[219] Rosenfeld C, Serra C, Brochon et al (2008) Use of micromixers to control the molecular weight distribution in continuous two-stage nitroxide-mediated copolymerizations. Chem. Eng. J. 135S: S242-S246

[220] Rosenfeld C, Serra C, Brochon et al (2008) Influence of micromixer characteristics on polydispersity index of block copolymers synthesized in continuous flow microreactors. Lab Chip 8: 1682-1687

[221] Miele S, Nesvadba P, Studer A (2009) 1-tert-Butyl-3,3,5,5-tetraalkyl-2piperazinon-4-oxyls: Highly efficient nitroxides for controlled radical polymerization. Macromolecules 42: 2419-2427

[222] Knoop CA, Studer A (2003) Hydroxy- and silyloxy-substituted TEMPO derivatives for the living free-radical polymerization of styrene and n-butyl acrylate: synthesis, kinetics, and mechanistic studies. J. Am. Chem. Soc. 125: 16327-16333

[223] Fukuyama T, Kajihara Y, Ryu I et al (2012) Nitroxide-mediated polymerization of styrene, butyl acrylate, or methyl methacrylate by microflow reactor technology. Synthesis 44: DOI: 10.1055/s-0031-1290780

[224] Rosenfeld C, Serra C, O’Donohue S et al (2007) Continuous online rapid size exclusion chromatography monitoring of polymerizations - CORSEMP. Macromol. React. Eng. 1: 547-552

[225] Zitlalpopoca-Soriano AG, Vivaldo-Lima E, Flores-Tlacuahuac A (2010) Bifurcation analysis of a tubular reactor for nitroxide-mediated radical polymerization of styrene. Macromol. React. Eng. 4: 599-612

[226] Zitlalpopoca-Soriano AG, Vivaldo-Lima E, Flores-Tlacuahuac A (2010) Grade transition dynamic optimization of the living nitroxide-mediated radical polymerization of styrene in a tubular reactor. Macromol. React. Eng. 4: 516-533 [227] Stridsberg, K. M.; Ryner, M.; Albertsson, A. C. Controlled ring opening polymerization: polymers with controlled architecture. In Advances in Polymers Science; Albertsson, A. C., Ed.; Springer-Verlag: Berlin, 2002.

[228] Sanda F, Endo T (1999) Syntheses and functions of polymers based on amino acids, Macromol. Chem. Phys. 200: 2651-2661

[229] Deming TJ (2000) Living polymerization of $\alpha$-amino acid- $N$ carboxyanhydrides. J. Polym. Sci. Part A: Polym. Chem. 38: 3011-3018

[230] Bamfold CH, Block H (1961) The initiation step in the polymerization of $N$ carboxy $\alpha$-amino acid anhydrides. J. Chem. Soc. 4989-4991

[231] Honda T, Miyazaki M, Nakamura H et al (2005) Controllable polymerization of $\mathrm{N}$-carboxy anhydrides in a microreaction system. Lab Chip 5: 812-818 
[232] Yamaguchi Y, Ogino K, Yamashita K et al (2004) Rapid micromixing based on multilayer laminar flows, J. Chem. Eng. J. 37: 1265-1270

[233] Miyazaki M, Honda T, Nakamura H et al (2007) Development of a microreactor for amino acid polymerization. Chem. Eng. Technol. 30: 300-304

[234] Kainthan RK, Janzen J, Levin E et al (2006) Biocompatibility testing of branched and linear polyglycidol. Biomacromolecules 7: 703-709

[235] Wilms D, Nieberle J, Klos J et al (2007) Synthesis of hyperbranched polyglycerol in a continuous flow microreactor. Chem. Eng. Technol. 30: 15191524

[236] Paulus RM, Erdmenger T, Becer CR et al (2007) Scale-Up of Microwaveassisted polymerizations in continuous-flow mode: Cationic ring-opening polymerization of 2-ethyl-2-oxazoline. Macromol. Rapid Commun. 28: 484-491 [237] Rogers ME, Long TE (2003) Turner in synthetic methods in step-growth polymers (Ed(s).: M. E. Rogers, T. E. Long), John Wiley \& Sons, Inc., Chichester West Sussex, England, Chapter 1.

[238] Kuboyama T, Yoshida J (2005) Synthesis of terminally modified polymer with a micromixer. Proc. of the $8^{\text {th }}$ Int. Conf. on Microreaction Technology (IMRET8) 132d.

[239] Liu S, Chang CH (2007) High rate convergent synthesis and deposition of polyamide dendrimers using a continuous-flow microreactor. Chem. Eng. Technol. 30: 334-340

[240] Miller RD (1999) In search of low-k dielectrics. Science 286: 421-423

[241] Chiang CL, Ma CCM (2003) Synthesis, characterization and properties of novolac ladder-like polysilsesquioxanes containing phosphorus. J. Polym Sci. Part A: Polym. Chem. 41: 1371-1379

[242] Kessler D, Theato P (2008) Synthesis of functional inorganic-organic hybrid polymers based on poly(silsesquioxanes) and their thin film properties Macromolecules 41: 5237-5244

[243] de Boer B, Simon HK, Werts MPL et al (2000) "Living” free radical photopolymerization initiated from surface-grafted iniferter monolayers Macromolecules 33: 349-356

[244] Kessler D, Löwe H, Theato P (2009) Synthesis of defined poly(silsesquioxane)s: fast polycondensation of trialkoxysilanes in a continuousflow microreactor. Macromol. Chem. Phys. 210: 807-813

[245] Andresen A, Cordes HG, Herwig H et al (1976) Influence of long-chain branching on the viscoelastic properties of low-density polyethylenes. Angew. Chem. Int. Ed. 15: 630-632

[246] Sinn H, Kaminsky W, Vollmer HJ et al (1980) Living polymers on polymerization with extremely productive Ziegler catalysts. Angew. Chem. Int. Ed. 19: 390-392

[247] Santos LS, Metzger JO (2006) Study of homogeneously catalyzed ZieglerNatta polymerization of ethene by ESI-MS. Angew. Chem., Int. Ed. 45: 977-981

[248] Luo N, Hutchinson JB, Anseth KS et al (2002) Integrated surface modification of fully polymeric microfluidic devices using living radical photopolymerization chemistry. J. Polym. Sci., Part A: Polym. Chem. 40: 18851891 
[249] Luo N, Metters AT, Hutchison JB et al (2003) Methacrylated photoiniferter as a chemical basis for microlithography: micropatterning based on photografting polymerization. Macromolecules 36: 6739-6745

[250] Hutchison JB, Haraldsson KT, Good BT et al (2004) Robust polymer microfluidic device fabrication via contact liquid photolithographic polymerization (CLiPP). Lab Chip 4: 658-662

[251] Simms HM, Brotherton CM, Good BT et al (2005) In situ fabrication of macroporous polymer networks within microfluidic devices by living radical photopolymerization and leaching. Lab Chip 5: 151-157

[252] Xu C, Wu T, Drain CM et al (2005) Microchannel confined surface-initiated polymerization. Macromolecules 38: 6-8

[253] Jeon NL, Dertinger SKW, Chiu DT et al (2000) Generation of solution and surface gradients using Microfluidic systems. Langmuir 16: 8311-8316

[254] Dertinger SKW, Chiu DT, Jeon NL et al (2001) Generation of gradients having complex shapes using microfluidic networks. Anal. Chem. 73: 1240-1246

[255] Jiang X, Xu Q, Dertinger SKW et al (2005) A general method for patterning gradients of biomolecules on surfaces using microfluidic networks. Anal. Chem. 77: 2338-2347

[256] Stroock A, Dertinger SKW, Ajdari A et al (2002) Chaotic mixer for microchannels. Science 295: 647-651

[257] Xu C, Barnes SE, Wu T et al (2006) Solution and surface composition gradients via microfluidic confinement: Fabrication of a statistical-copolymerbrush composition gradient. Adv. Mater. 18: 1427-1430

[258] Burdick JA, Khademhosseini A, Langer R (2004) Fabrication of gradient hydrogels using a microfluidics/photopolymerization process. Langmuir 20: 51535156

[259] Atencia J, Beebe DJ (2005) Controlled microfluidic interfaces, Nature 437: 648-655

[260] Weigl BH, Yager P (1999) Microfluidic diffusion-based separation and detection. Science 283: 346-347

[261] Kenis PJA, Ismagilov RF, Whitesides GM (1999) Microfabrication Inside Capillaries Using Multiphase Laminar Flow Patterning. Science 285: 83-85

[262] Kenis PJA, Ismagilov RF, Takayama S et al (2000) Fabrication inside microchannels using fluid flow. Acc. Chem. Res. 33: 841-847

[263] Zhao B, Viernes NOL, Moore JS et al (2002) Control and applications of immiscible liquids in microchannels, J. Am. Chem. Soc. 124: 5284-5285

[264] Hisamoto H, Shimizu Y, Uchiyama K et al (2003) Chemicofunctional membrane for integrated chemical processes on a microchip, Anal. Chem. 75: 350-354

[265] Uozumi Y, Yamada YMA, Beppu T et al (2006) Instantaneous carboncarbon bond formation using a microchannel reactor with a catalytic membrane. J. Am. Chem. Soc. 128: 15994-15995

[266] Yamada YMA, Torii K, Uozumi Y (2009) Oxidative cyclization of alkenols with Oxone using a miniflow reactor. Beilstein J. Org. Chem. 5: No. 18. 
[267] Yamada YMA, Watanabe T, Torii K et al (2009) Catalytic membraneinstalled microchannel reactors for one-second allylic arylation. Chem. Commun. 5594-5596

[268] Yamada YMA, Watanabe T, Torii K et al (2010) Palladium membraneinstalled microchannel devices for instantaneous Suzuki-Miyaura cross-coupling. Chem. Eur. J. 16: 11311-11319

[269] Yamada YMA, Watanabe T, Ohno A et al (2012) Development of polymeric palladium-nanoparticle membrane-installed microflow devices and their application in hydrodehalogenation. ChemSusChem 5: 293-299

[270] Gargiuli J, Shapiro E, Gulhane H et al (2006) Microfluidic systems for in situ formation of nylon 6,6 membranes, J. Membrane Sci. 282: 257-265

[271] Honda T, Miyazaki M, Nakamura H et al (2006) Facile preparation of an enzyme-immobilized microreactor using a cross-linking enzyme membrane on a microchannel surface. Adv. Synth. Catal. 348: 2163-2171

[272] Cao L, Langen L, Sheldon RA (2003) Immobilised enzymes: carrier-bound or carrier-free? Curr. Opin. Biotechnol. 14: 387-394 